\title{
Complications of Cushing's syndrome: state of the art
}

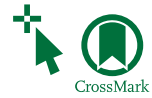

Rosario Pivonello*, Andrea M Isidori*, Maria Cristina De Martino, John Newell-Price, Beverly M K Biller, Annamaria Colao

Cushing's syndrome is a serious endocrine disease caused by chronic, autonomous, and excessive secretion of cortisol. The syndrome is associated with increased mortality and impaired quality of life because of the occurrence of comorbidities. These clinical complications include metabolic syndrome, consisting of systemic arterial hypertension, visceral obesity, impairment of glucose metabolism, and dyslipidaemia; musculoskeletal disorders such as myopathy, osteoporosis, and skeletal fractures; neuropsychiatric disorders, such as impairment of cognitive function, depression, or mania; impairment of reproductive and sexual function; and dermatological manifestations, mainly represented by acne, hirsutism, and alopecia. Hypertension in patients with Cushing's syndrome has a multifactorial pathogenesis and contributes to the increased risk for myocardial infarction, cardiac failure, or stroke, which are the most common causes of death; risks of these outcomes are exacerbated by a prothrombotic diathesis and hypokalaemia. Neuropsychiatric disorders can be responsible for suicide. Immune disorders are common; immunosuppression during active disease causes susceptibility to infections, possibly complicated by sepsis, an important cause of death, whereas immune rebound after disease remission can exacerbate underlying autoimmune diseases. Prompt treatment of cortisol excess and specific treatments of comorbidities are crucial to prevent serious clinical complications and reduce the mortality associated with Cushing's syndrome.

\section{Introduction}

Cushing's syndrome, or chronic endogenous hypercortisolism, is a serious endocrine disease caused by chronic, autonomous, and excessive secretion of cortisol from the adrenal glands, with an estimated prevalence of around 40 cases per million and an estimated incidence of $0 \cdot 7-2 \cdot 4$ cases per million per year, although the worldwide epidemiology has not been fully determined. ${ }^{1-3}$ Cushing's syndrome is at least three times more prevalent in women than in men, and although it can occur at any age, is more frequent during the fourth to sixth decades of life. ${ }^{1-4}$ In the great majority of cases (around 70\%), Cushing's syndrome is caused by a pituitary tumour producing excessive adrenocorticotropic hormone (ACTH) that stimulates excessive cortisol secretion from the adrenal cortex, which is termed pituitary-dependent Cushing's syndrome or Cushing's disease. ACTH-independent adrenal production of cortisol by an adrenal tumour or bilateral adrenal hyperplasia or dysplasia is responsible for around $20 \%$ of cases of Cushing's syndrome. An extrapituitary tumour secreting ACTH or, very rarely, corticotropin-releasing hormone, causes ectopic Cushing's syndrome in the remaining roughly $10 \%$ of cases. ${ }^{1-4}$ Cushing's syndrome can also be caused by excessive exposure to exogenous glucocorticoids, which is termed exogenous Cushing's syndrome. ${ }^{1,2}$

In 1932, Harvey Cushing first recognised a constellation of symptoms and signs in a group of patients, including obesity with adiposity localised on the face and trunk, wasting of the arm and leg musculature, with muscular weakness and fatigue, purplish striae on the abdomen, telangiectasias of the face, diffuse ecchymoses, hypertension, hyperglycaemia, osteoporosis, depression, susceptibility to infections, menstrual irregularity in women, and decrease of libido in men. ${ }^{5}$ Most of these clinical manifestations are nowadays recognised as the main clinical features and complications associated with Cushing's syndrome. The clinical picture of Cushing's syndrome consists of weight gain with central obesity, fatigue with proximal myopathy, skin thinning with purplish striae, and easy bruising. Several comorbidities are associated with Cushing's syndrome $e^{1,2,4}$ and are responsible for an impairment of quality of life and an increase in mortality. ${ }^{6}$

The diagnosis and determination of the origin of Cushing's syndrome can be challenging and time-consuming, and requires different laboratory tests and imaging procedures. ${ }^{7-9}$ Prompt and effective treatment is crucial for the reversal of comorbidities, prevention of serious acute and chronic complications, and protection from the increased mortality risk (panel 1).,10,11 Notably, the increased mortality and morbidity that affect patients with Cushing's syndrome during the active phase of the disease might not completely revert after disease remission (ie, resolution of hypercortisolism after an effective treatment). The reasons why surely morbidity and possibly mortality remain increased after remission of Cushing's syndrome remain unclear. Beyond the irreversible damage of organs and systems induced by long-term cortisol excess, reasons that morbidity and mortality remain increased might include glucocorticoid withdrawal syndrome or adrenal insufficiency, which can result from treatment for Cushing's syndrome, or non-physiological adrenal replacement therapy in patients with adrenal insufficiency after treatment for Cushing's syndrome (panel 2). ${ }^{1,10-14}$

In this Review, we summarise key studies on mortality risk, and focus on the comorbidities and clinical complications of the different types of endogenous Cushing's syndrome. We present a detailed description of the pathophysiology of the comorbidities together with a systematic analysis of the studies on mortality and metabolic, skeletal, infectious, and autoimmune
Lancet Diabetes Endocrinol 2016 Published Online May 10, 2016 http://dx.doi.org/10.1016/ S2213-8587(16)00086-3

*Contributed equally

Dipartimento di Medicina Clinica e Chirurgia, Sezione di Endocrinologia, Università Federico II di Napoli, Naples, Italy (Prof R Pivonello PhD MC De Martino PhD, Prof A Colao PhD); Department of Experimental Medicine, Sapienza University of Rome, Rome, Italy (Prof A M Isidori PhD); Department of Oncology and Metabolism, The Medical School, University of Sheffield Sheffield, UK (Prof J Newell-Price PhD); The Endocrine Unit, The Royal Hallamshire Hospital, Sheffield Teaching Hospitals NHS Foundation Trust, Sheffield, UK (ProfJ Newell-Price); and Neuroendocrine Unit, Department of Medicine, Massachusetts General Hospital, Harvard Medical School, Boston, MA, USA (Prof B M K Biller MD)

Correspondence to: Prof Rosario Pivonello, Dipartimento di Medicina Clinica e Chirurgia, Sezione di Endocrinologia, Università Federico II di Napoli, 80131 Naples, Italy rosario.pivonello@unina.it 
Panel 1: Specific treatments for the various types of Cushing's syndrome ${ }^{1,2,10,11}$

- Management of adrenocorticotropic hormone (ACTH)-dependent Cushing's syndrome requires a multidisciplinary and individualised approach. In general, the treatment of choice for ACTH-dependent Cushing's syndrome is curative surgery with selective pituitary or ectopic corticotroph tumour resection, although this is not always possible or effective.

- In Cushing's disease, second-line treatments include repeat pituitary surgery (generally with a more radical approach), pituitary radiotherapy, adrenal surgery (generally bilateral adrenalectomy), and pharmacological therapy.

- In ectopic Cushing's syndrome, second-line treatments include radical surgery, radiotherapy, or chemotherapy, depending on the tumour responsible for the disease and the disease stage.

- ACTH-independent Cushing's syndrome is usually treated by adrenal surgery, with the removal of the adrenal gland where the tumour is located, and less frequently with the removal of both glands, but rarely or transiently it can be treated with pharmacological therapy.

- In patients with a malignant adrenal tumour, extensive surgery and/or radiotherapy or chemotherapy might be necessary.

- Pharmacological therapy for Cushing's syndrome consists of three categories of drugs:

- Adrenal-directed agents, which block cortisol production through inhibition of steroidogenesis enzymes-eg, ketoconazole and metyrapone (approved in the European Union for treatment of (ushing's syndrome), and mitotane (generally off-label indication, apart from adrenal cancer);

- Pituitary-directed drugs, which act at the level of the pituitary tumour, inhibiting ACTH secretion, and which are useful for the treatment of Cushing's disease-eg, pasireotide (approved worldwide for treatment of Cushing's disease when surgery is not an option) and cabergoline (off-label indication);

- Glucocorticoid receptor-directed drugs which peripherally block the glucocorticoid receptor-eg, mifepristone (approved in the USA for patients with hyperglycaemia when surgery is not an option).

See Online for appendix complications associated with types of Cushing's syndrome, during both active and remission phases of disease, where such information was available in the scientific literature. Finally, to aid clinicians who manage patients with active Cushing's syndrome as well as those in remission, we discuss approaches that can be used in clinical practice for prevention of complications, such as antithrombotic and anti-infective prophylaxis. Notably, most reported studies on the clinical complications of Cushing's syndrome do not represent high-quality evidence.

\section{Mortality}

Cushing's syndrome is associated with excessive mortality, which is mainly caused by cardiovascular or infectious diseases, and their systemic consequences, mainly myocardial infarction, stroke, and sepsis. ${ }^{15}$ The excess mortality is usually seen in patients who do not achieve initial surgical remission, whereas in patients with postoperative hormonal control, mortality was described to be either increased or similar to that in the general population. ${ }^{15}$ In the past two decades, several studies have investigated the increased mortality from Cushing's syndrome, primarily focusing on Cushing's disease. 11 national or single-centre studies reported the standardised mortality ratio (SMR) of patients with Cushing's syndrome, ${ }^{16-26}$ with variable findings: six focused only on Cushing's disease $\mathrm{e}^{16,17,20-23}$ and five also assessed patients with adrenal or ectopic Cushing's syndrome..$^{18,19,24-26}$ See appendix for a systematic analysis of the studies on mortality that reported the SMR in Cushing's syndrome. In patients with Cushing's disease, the overall SMR ranged from 0.98 to $9 \cdot 3,,^{16-26}$ being similar to ${ }^{17-20,25}$ or significantly higher ${ }^{16,21-24,26}$ than the general population. There is consistent evidence that patients with persistent disease after pituitary surgery have the highest mortality. By contrast, data are discordant for patients with disease remission after treatment; several studies showed an SMR similar to that of the general population, ${ }^{19-21,25}$ but an increased SMR was reported in three different UK studies and one New Zealand study. ${ }^{22-24,26}$

Cardiovascular disease is the major cause of death in patients with Cushing's disease, either during active disease or after remission. Infectious diseases and sepsis represent frequent causes of death, and suicide associated with psychiatric disorders has also been described in patients with Cushing's disease. ${ }^{6,15-26}$ The main predictive factors for mortality have been identified as older age at diagnosis, the presence and duration of active disease, and the presence of comorbidities, mainly hypertension and diabetes. ${ }^{27,28} \mathrm{~A}$ recent meta-analysis on mortality in patients with Cushing's syndrome, which included six studies that focused on patients with Cushing's disease, confirmed that Cushing's disease is associated with increased mortality (SMR 1.84, 95\% CI $1 \cdot 28-2 \cdot 65)$, with highest mortality in patients with persistent or recurrent disease $(3 \cdot 73,2 \cdot 31-6 \cdot 01)$. By contrast, mortality in patients with cured disease after initial pituitary surgery (SMR $1 \cdot 23,95 \%$ CI $0 \cdot 51-2 \cdot 97$ ) does not significantly differ to that of the general population. ${ }^{29}$ This meta-analysis is in accordance with several available studies, suggesting that remission induced by surgery is crucial to protect patients with Cushing's disease from premature death, although this concept is still debated and needs further studies to draw a definitive conclusion.

In patients with adrenal-dependent Cushing's syndrome, including patients with benign adrenal pathology, the SMR varied substantially, from 1.35 to $7 \cdot 5,,^{18,19,24-26}$ in adrenal adenomas, and from $1 \cdot 14$ to 12 in bilateral adrenal hyperplasia, ${ }^{18,24,25}$ being higher, ${ }^{18,24}$ similar, ${ }^{19,25}$ or lower ${ }^{26}$ than that reported in patients with Cushing's disease. The main causes of death were cardiovascular and cerebrovascular disease, thromboembolism, infectious diseases or sepsis, and suicide. Patients with adrenal carcinoma, which carries a very poor prognosis, had a substantially increased SMR up to $48.00 \quad(95 \%$ CI $30 \cdot 75-71.42)$, mainly because of neoplastic progression or pulmonary thromboembolism..$^{25,26}$ 
Panel 2: Adrenal insufficiency and glucocorticoid withdrawal syndrome after resolution of hypercortisolism ${ }^{1,10-14}$

Successful treatment of Cushing's syndrome might induce adrenal insufficiency, which can last for several months to several years, because of suppression of the hypothalamic-pituitaryadrenal (HPA) axis, but can be permanent if the HPA axis does not recover. After remission from Cushing's syndrome, replacement therapy with glucocorticoids is used for adrenal insufficiency. Hydrocortisone $10-20 \mathrm{mg} / \mathrm{m}^{2}$ in two to three daily doses is the optimum current therapy, with half to two-thirds of the total dose taken in the morning; its short half-life might facilitate HPA axis recovery. Conversely, long-acting glucocorticoids should be avoided because they might prolong HPA axis suppression, and they have adverse metabolic consequences. Close monitoring of the HPA axis is needed, however, and morning serum cortisol concentrations before administration of glucocorticoids should be assessed approximately every 3 months for the first 2 years. Three main outcomes are found: (1) a concentration of $500 \mathrm{nmol} / \mathrm{L}$ $(18 \mu \mathrm{g} / \mathrm{dL})$ or more means the HPA axis has recovered and glucocorticoids can be discontinued; (2) a concentration of less than $200 \mathrm{nmol} / \mathrm{L}$ mandates continuance of glucocorticoid therapy; and (3) concentrations ranging from $200 \mathrm{nmol} / \mathrm{L}$ $(7 \mu \mathrm{g} / \mathrm{dL})$ to $500 \mathrm{nmol} / \mathrm{L}$ are associated with incomplete HPA axis recovery; therefore, an adrenocorticotropic hormone stimulation test is recommended with stimulated serum cortisol concentrations of less than $500 \mathrm{nmol} / \mathrm{L}(18 \mu \mathrm{g} / \mathrm{dL})$ identifying persisting adrenal insufficiency, and higher concentrations allowing discontinuation of glucocorticoids.

In general, use of supraphysiological glucocorticoid doses is associated with increased morbidity and mortality, mainly from cardiovascular diseases. Therefore, adrenal insufficiency replacement therapy should be tailored to each patient's needs, avoiding over-treatment and under-treatment (which might make adrenal insufficiency crises more likely). Another challenge is the need to replicate the physiological circadian rhythm of cortisol secretion. Standard hydrocortisone regimens result in supraphysiological circulating cortisol peaks, especially after afternoon and evening dosing, when concentrations of serum cortisol in healthy individuals are usually low. The inadequacies of current hydrocortisone regimens might have a role in the impaired glucose tolerance or diabetes, visceral obesity, hypertension, alterations of bone metabolism, and decreased quality of life seen in some patients with Cushing's syndrome even after remission, and so contribute to residual mortality.

Patients in remission owing to Cushing's syndrome treatment might also have glucocorticoid withdrawal syndrome, in which a rapid decrease in circulating cortisol concentrations after previous chronic overexposure is associated with lack of wellbeing and even a flu-like syndrome, which might mimic adrenal insufficiency, even in the presence of normal circulating cortisol concentrations. This disorder can be very challenging to manage. One strategy is to use pharmacological therapy to slightly reduce cortisol concentrations before definitive treatment for Cushing's syndrome, whereas another more practical approach is to give glucocorticoids at higher than optimum replacement doses for several weeks after remission, but then to taper these as soon as possible, according to individual patient symptoms, so as to avoid inducing iatrogenic Cushing's syndrome.
In patients with ectopic Cushing's syndrome, SMR ranged from $13 \cdot 3$ to $68 \cdot 5$, as expected for the frequently malignant origin or aggressive behaviour of the disease. ${ }^{24-26}$ Beyond neoplastic progression, causes of death were typically infectious diseases or sepsis; one study noted skeletal complications as a cause of death..$^{25}$

\section{Morbidity}

The excessive mortality associated with Cushing's syndrome is a direct consequence of the multiple comorbidities affecting patients with this syndrome (figure 1). These comorbidities include a specific form of metabolic syndrome, characterised by hypertension, visceral obesity, impairment of glucose metabolism, and dyslipidaemia. This metabolic syndrome is strictly associated with cardiovascular disease, including vascular atherosclerosis and cardiac damage, which, together with thromboembolism and hypokalaemia, contribute to the increase in cardiovascular risk.,2,4 Additional clinical complications include musculoskeletal diseases, such as myopathy, osteoporosis, and skeletal fractures, as well as neuropsychiatric diseases, such as impairment of cognitive function, and psychiatric disorders, including mania or depression, which can result in suicide. ${ }^{1,2,4}$ An important complication of Cushing's syndrome is the impairment of immune function, associated with severe infections or sepsis during active disease, which are a direct consequence of increased cortisol secretion. The decrease in cortisol during remission may result in immune rebound, which can induce a flare of underlying autoimmune disorders. An impairment of reproductive and sexual function is frequently present in both men and women. In both sexes, dermatological manifestations are also common, but specific dermatological features (eg, acne, hirsutism, and alopecia) are typically associated with female sex.1,2,4 Morbidity can be increased in the long term, being present before diagnosis and remaining in several patients even after many years of remission. ${ }^{28}$

\section{Metabolic syndrome \\ Pathogenesis}

Glucocorticoids regulate metabolism, and chronic hypercortisolism can lead to a specific form of the metabolic syndrome. ${ }^{28,30}$ Glucocorticoid excess affects a range of metabolic pathways determining the different 


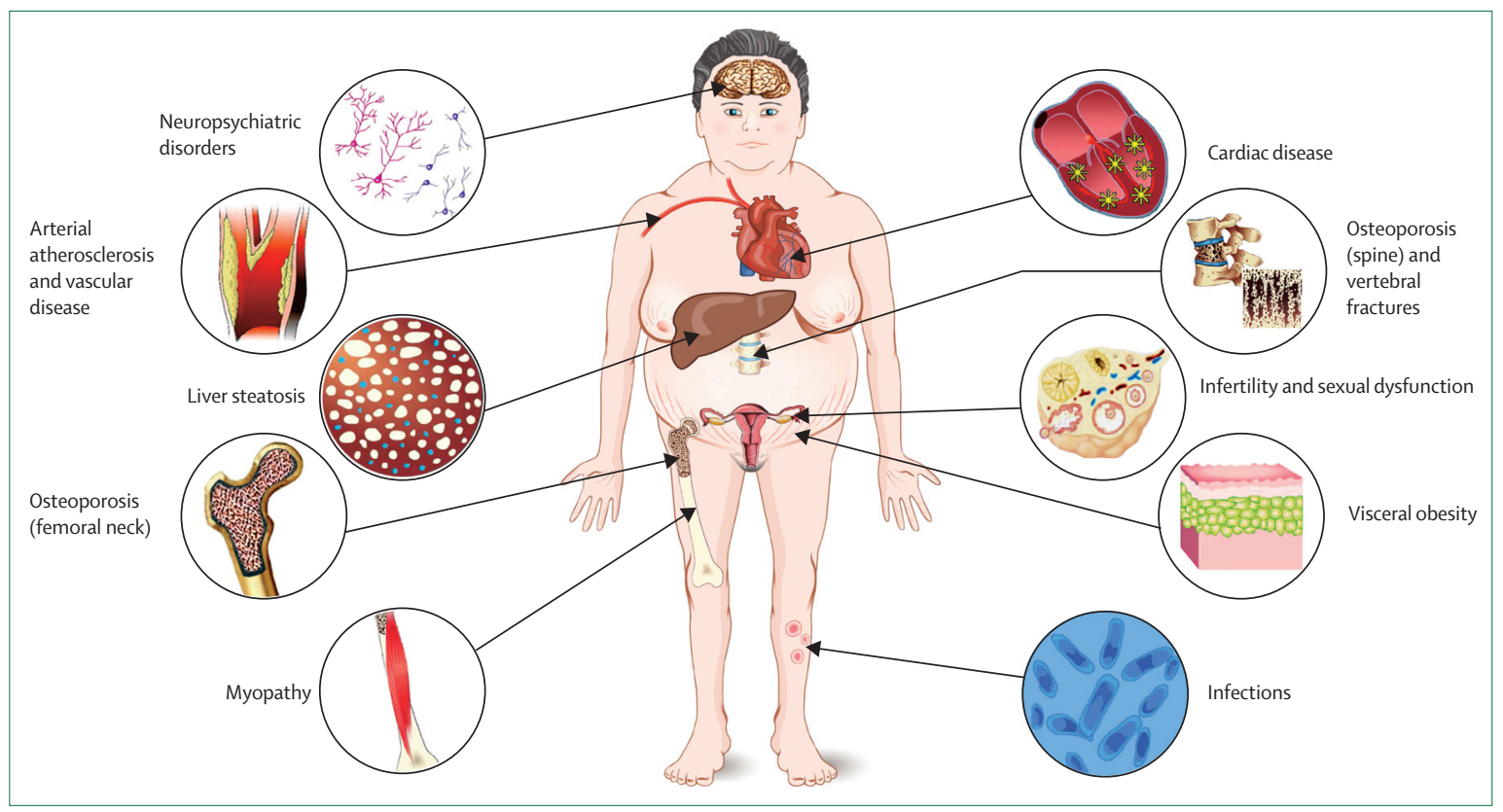

Figure 1: Main comorbidities and clinical complications associated with mortality in patients with Cushing's syndrome

manifestations of this metabolic syndrome (figure 2). Glucocorticoids stimulate key enzymes involved in liver gluconeogenesis, increasing glucose output and circulating glucose concentrations, ${ }^{31,32}$ and cause hepatic and peripheral insulin resistance by direct and indirect mechanisms. ${ }^{31}$ Glucocorticoids also interfere with the insulin-stimulated translocation of glucose transporters (GLUT4) to the plasma membrane, thereby decreasing glucose uptake. $^{32}$ In adipose tissue, glucocorticoids promote pre-adipocyte differentiation into adipocytes and decrease lipogenesis, also enhancing insulininduced lipogenesis..$^{33}$ In adipose tissue and skeletal muscle, glucocorticoids reduce aminoacid uptake and increase lipid oxidation and lipolysis, whereas in the liver, glucocorticoids promote lipoprotein secretion and stimulate enzymes involved in fatty acid synthesis, contributing to the development of liver steatosis and impairing insulin sensitivity. ${ }^{31}$ These processes all contribute to glucocorticoid-induced insulin resistance, a major feature of the metabolic syndrome. ${ }^{30}$ In animal models, glucocorticoids inhibit pancreatic insulin secretion and in human beings they alter high-frequency insulin release in the fasting state. ${ }^{32}$ In line with these findings, the alterations of glucose metabolism seen in patients with Cushing's syndrome have been attributed to both glucocorticoid-induced insulin resistance and inadequate pancreatic $\beta$-cell compensation. ${ }^{32}$ Central effects of glucocorticoids on appetite have also been reported. ${ }^{34}$

Chronic hypercortisolism is mainly associated with abdominal obesity with preferential visceral fat accumulation..$^{33}$ The mechanisms underlying typical fat distribution pattern are only partly understood.
The enzyme 11 -hydroxysteroid dehydrogenase type 1 (11 $\beta$-HSD1) converts inactive cortisone to active cortisol, and differential $11 \beta$-HSD1 expression in tissues might affect local cortisol availability. ${ }^{33} 11 \beta$-HSD1-knockout mice are protected from diet-induced obesity; conversely, animals overexpressing 11ß-HSD1 have metabolic syndrome and visceral obesity. ${ }^{33}$ Therefore, differential expression of 11 $\beta$-HSD1 in visceral versus subcutaneous adipose tissue might affect the fat distribution pattern, but data from human studies are scarce. Glucocorticoids exert their effects by binding glucocorticoid receptor types 1 and 2, and it has recently been suggested that varying expression of these receptors and their isoforms in different tissues might influence the tissue-specific actions of glucocorticoids, contributing to the disparate effects observed in visceral and subcutaneous adipose tissue. ${ }^{33}$ The visceral adipose tissue in patients with Cushing's syndrome has been reported to be structurally and functionally different from that in people without Cushing's syndrome; indeed, enlarged abdominal fat cells, increased lipoprotein lipase activity, and decreased lipolytic capacity were reported in female patients with Cushing's syndrome compared with women without Cushing's syndrome, ${ }^{33}$ whereas increased lipogenesis has been recorded in patients with Cushing's syndrome compared with obese controls. ${ }^{35}$ The preferential accumulation of visceral fat in Cushing's syndrome is associated with abnormal adipokine production, which might contribute to the development of metabolic syndrome. ${ }^{32}$ See appendix for a systematic analysis of studies on the metabolic syndrome in Cushing's syndrome. 


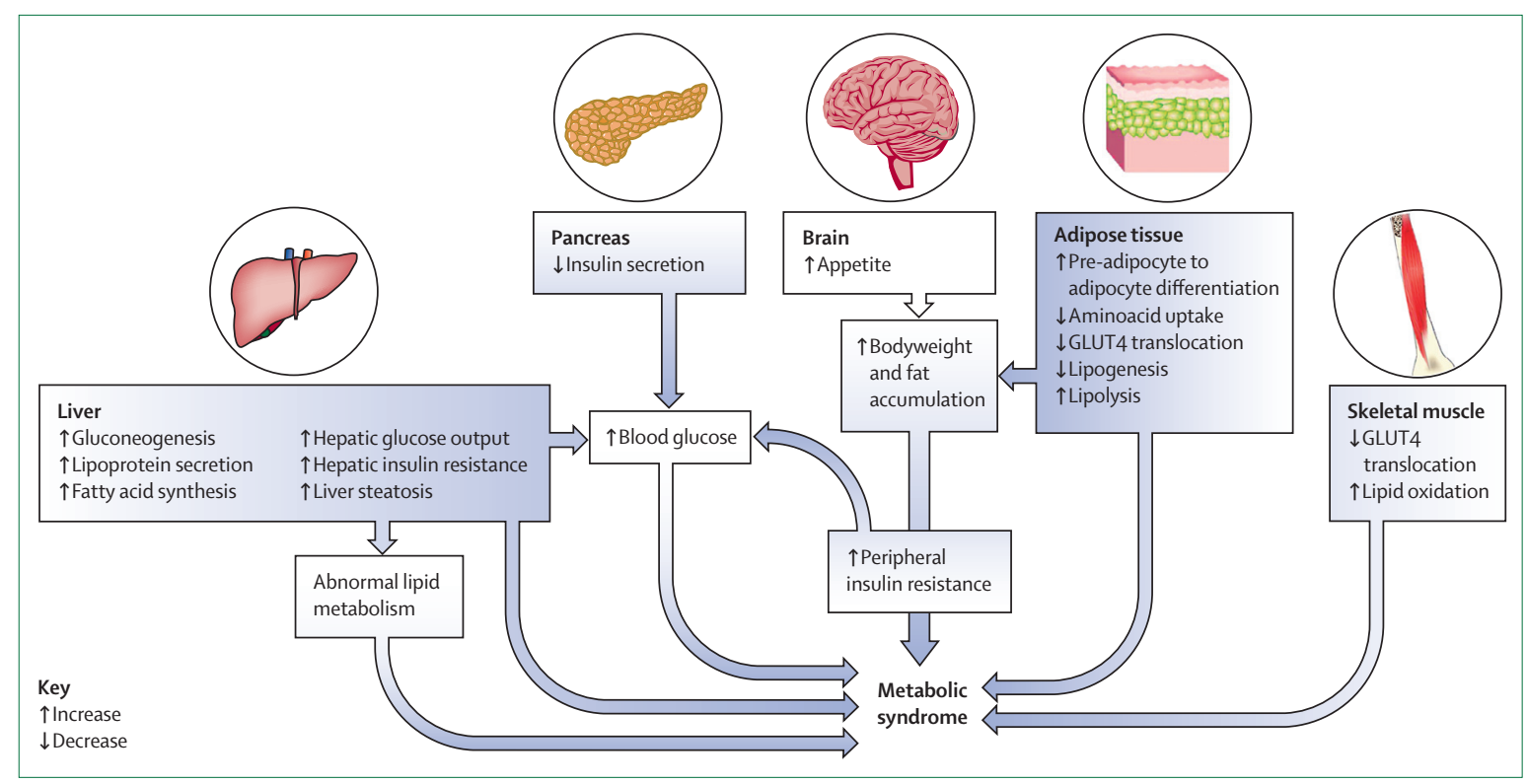

Figure 2: Main pathogenic mechanisms underlying the development of metabolic syndrome in patients with Cushing's syndrome Circled images represent the main organs that have a role in the metabolic abnormalities seen in patients with Cushing's syndrome; the text below each organ describes the main mechanisms involved in the pathogenesis of these metabolic abnormalities and the main metabolic abnormalities determining metabolic syndrome in patients with Cushing's syndrome. $\uparrow$ indicates increased; $\downarrow$ indicates decreased. GLUT4=glucose transporter type 4.

\section{Visceral obesity}

Weight excess, as documented by the pathological increase in BMI, is among the most common features of Cushing's syndrome; indeed, weight excess is seen in $57-100 \%$ of patients (overweight in $33-48 \%$ and obesity in $25-100 \%) .^{23,36-43}$ However, the obesity associated with Cushing's syndrome is abdominal rather than generalised weight gain, with preferential visceral rather than subcutaneous accumulation of fat tissue, ${ }^{36-40}$ as reported in studies using whole body magnetic resonance imaging. ${ }^{41}$ In a study of patients with pituitary or adrenal Cushing's syndrome, waist circumference, a simple marker of visceral obesity, was significantly higher in cases than in BMI-matched controls $(\mathrm{p}=0 \cdot 0001)$, without significant differences among types of Cushing's syndrome. ${ }^{38}$ A pivotal role of visceral obesity in determining hypercortisolism-induced metabolic alterations is substantiated by a correlation of waist-to-hip ratio, another marker of visceral obesity, with blood pressure, glucose concentration, and insulin concentration in patients with Cushing's syndrome. ${ }^{36}$ The duration of hypercortisolism correlates with the presence of obesity. ${ }^{37}$ Female patients with Cushing's syndrome have a higher BMI than male patients, ${ }^{44}$ although the prevalence of obesity is similar between men and women. ${ }^{45}$ Remission from hypercortisolism can improve, but does not consistently normalise weight excess, which can persist after short-term (1-year) or long-term (5-year) surgical remission. .,38,40 $^{3}$ Two studies have reported an improvement in waist-to-hip ratio or waist circumference 1 year after surgical remission, particularly in patients with adrenal Cushing's syndrome, although these parameters remained increased compared with controls..$^{36,38}$

Pharmacological treatment can ameliorate excess weight in Cushing's syndrome. ${ }^{46-55}$ In patients with various types of Cushing's syndrome, 3 months' treatment with ketoconazole reduced weight from $1 \mathrm{~kg}$ to $10 \mathrm{~kg}$ in about half of patients who were overweight or obese at baseline. ${ }^{49}$ Control of hypercortisolism after 6 months' treatment with mitotane significantly reduced BMI (from median $28 \cdot 3$ [range 19.3-51.7] at baseline to $26 \cdot 2[16 \cdot 3-46 \cdot 3]$ after treatment; $p<0 \cdot 0001$ ) in patients with Cushing's disease, ${ }^{50}$ and treatment with mifepristone improved weight in patients with Cushing's syndrome versus baseline. ${ }^{53}$ Among pituitary-directed drugs, pasireotide reduced weight (by $-4.4 \mathrm{~kg}$ at 6 months, and $-6.7 \mathrm{~kg}$ at 12 months), BMI $\left(-1.6 \mathrm{~kg} / \mathrm{m}^{2}\right.$ and $\left.-2.5 \mathrm{~kg} / \mathrm{m}^{2}\right)$, and waist circumference $(-2.6 \mathrm{~cm}$ and $-5.0 \mathrm{~cm})$ even without complete biochemical control, ${ }^{55}$ whereas cabergoline improved waist-to-hip ratio after short-term treatment ( 1.10 at baseline vs 1.08 after 3 months) and reduced BMI after long-term treatment $\left(28 \cdot 2 \mathrm{~kg} / \mathrm{m}^{2}\right.$ vs $27 \cdot 1 \mathrm{~kg} / \mathrm{m}^{2}$ after 24 months $)^{46}$ in patients with Cushing's disease versus baseline.

\section{Impairment of glucose metabolism}

An impairment of glucose metabolism has been described in $27-87 \%$ of patients with Cushing's syndrome; in particular, impaired glucose tolerance is described in $7-64 \%$ of patients and diabetes in $11-47 \%$ of patients, whereas impaired fasting glucose has been less frequently investigated and reported in $6-14 \%$ of 
patients. ${ }^{16,23,24,26-28,36-38,40-44,56}$ Glucose and insulin concentrations were higher in patients with Cushing's disease compared with sex and age-matched controls and compared with BMI-matched controls after glucose loading, ${ }^{36}$ suggesting that some effects are independent of weight. The prevalence of impaired glucose tolerance or diabetes was higher in patients with pituitary or adrenal Cushing's syndrome than in BMI-matched controls. ${ }^{38}$ No difference between the two disease types ${ }^{38}$ or between sexes ${ }^{45}$ has been reported. However, the prevalence of diabetes in patients with ectopic Cushing's syndrome (74\%) is higher than in patients with other types of Cushing's syndrome-eg, 33\% in pituitary and $34 \%$ in adrenal Cushing's syndrome (both $\mathrm{p}<0 \cdot 01$ ). ${ }^{56}$ Remission from hypercortisolism can improve, but does not always normalise glucose abnormalities. ${ }^{57}$ 5 years after surgical remission, the prevalence of an abnormality in glucose metabolism remained higher in patients with Cushing's disease than in controls. ${ }^{40}$ In two studies, one exploring the effects of 1-year surgical remission in patients with pituitary and adrenal Cushing's syndrome, and one exploring these effects in patients with pituitary Cushing's syndrome only, glucose levels after an oral glucose tolerance test were slightly decreased compared with the active phase of disease and showed no significant difference from controls. ${ }^{36,38}$ However, a significant reduction in the prevalence of impaired glucose tolerance was noted only in patients with adrenal Cushing's syndrome ( $7 \% 1$ year after remission $v$ s $40 \%$ at baseline, $\mathrm{p}=0 \cdot 02$ ), ${ }^{38}$ suggesting that abnormal glucose metabolism might recover faster with treatment in this population than in patients with Cushing's disease.

Generally, pharmacological treatment is associated with an improvement in glucose metabolism, with the exception of pasireotide. Adrenal-directed drugs positively affect glucose metabolism in patients with Cushing's syndrome. ${ }^{47-50,58}$ Mifepristone improved insulin sensitivity and diabetes control in patients with Cushing's syndrome. ${ }^{51-54}$ Among pituitary-directed drugs, cabergoline improved insulin sensitivity in the short term, and reduced the prevalence of impaired glucose tolerance or diabetes and reduced the requirement for antidiabetic medication during long-term treatment. ${ }^{46}$ By contrast, pasireotide worsened glycaemic control in patients with Cushing's disease, particularly in those with pre-existing alterations of glucose metabolism. .5,59 $^{5}$ Results from a study in healthy volunteers showed that pasireotide-induced hyperglycaemia is probably related to a direct inhibition of pancreatic insulin and gastrointestinal incretin secretion. ${ }^{60}$ Therefore, in patients on pasireotide treatment, glucose metabolism should be monitored and hyperglycaemia should be managed with metformin and a staged treatment intensification with a dipeptidyl peptidase-4 inhibitor or a glucagon-like peptide-1 receptor agonist, or with insulin, as required, to achieve and maintain glycaemic control. ${ }^{61}$

\section{Dyslipidaemia}

Dyslipidaemia has not been extensively investigated, but it is described in $12-72 \%$ of patients with Cushing's syndrome. $23,24,27,36-38,42,44$ Dyslipidaemia in Cushing's syndrome is commonly characterised by raised total and LDL cholesterol and triglyceride concentrations, and reduced HDL cholesterol concentrations. ${ }^{24,36,37,44}$ An abnormal lipid profile was noted in patients with pituitary and adrenal Cushing's syndrome compared with controls, ${ }^{36,38}$ with similar findings in patients with adrenal Cushing's syndrome. ${ }^{38}$ Dyslipidaemia persisted 1 year after surgical remission in patients with pituitary or adrenal Cushing's syndrome. ${ }^{36,38}$ A significant decrease in concentrations of total cholesterol $(5.6 \mathrm{mmol} / \mathrm{L}$ [SE $0 \cdot 2$ ] at baseline vs $4.3 \mathrm{mmol} / \mathrm{L}$ [0.2] after remission; $\mathrm{p}<0 \cdot 004$ ) and LDL cholesterol $(3.5 \mathrm{mmol} / \mathrm{L}[0 \cdot 2]$ vs $2.5 \mathrm{mmol} / \mathrm{L}$ $[0 \cdot 2] ; \mathrm{p}<0 \cdot 004)$ was reported after remission in patients with adrenal Cushing's syndrome, becoming similar to those in controls, without any significant change in the otherwise reported normal HDL cholesterol or triglyceride concentrations; in this study, no changes were seen in patients with Cushing's disease. ${ }^{38}$ However, in a study including patients with Cushing's disease only, a significant reduction in LDL cholesterol concentration (4.35 mmol/L [SE 0.6] at baseline vs 3.75 [0.5] after remission; $\mathrm{p}<0.05)$ was noted 1 year after surgical remission. ${ }^{36}$ After short-term (1-year) or long-term (5-year) remission, concentrations of total cholesterol and LDL cholesterol were higher than in sex-matched and age-matched, but not BMI-matched controls, suggesting that the persistence of obesity might contribute to the persistence of abnormal lipid profile..$^{36,40}$

The effects of pharmacological treatment on the lipid profile in Cushing's syndrome are variable. Mitotane treatment increased concentrations of total cholesterol (median $5.8 \mathrm{mmol} / \mathrm{L}$ [range 3.5-8.2] at baseline vs $7 \cdot 7 \mathrm{mmol} / \mathrm{L}[5 \cdot 1-14 \cdot 0]$ under treatment; $\mathrm{p}<0 \cdot 0001)$, LDL cholesterol $(3.7 \mathrm{mmol} / \mathrm{L}[1.4-5.7]$ vs $4.2 \mathrm{mmol} / \mathrm{L}$ [1.9-10.9]; $\mathrm{p}<0.05)$, and HDL cholesterol $(1.6 \mathrm{mmol} / \mathrm{L}$ $[0 \cdot 8-3 \cdot 1]$ vs $1.8 \mathrm{mmol} / \mathrm{L}[1 \cdot 0-3 \cdot 6] ; \mathrm{p}<0 \cdot 05)$, and triglycerides $(1.2 \mathrm{mmol} / \mathrm{L}[0.4-11.8]$ vs $1.6 \mathrm{mmol} / \mathrm{L}$ $[0 \cdot 6-5 \cdot 5] ; \mathrm{p}<0 \cdot 01)$ in patients with Cushing's disease. ${ }^{50}$ Conversely, a reduction in total $(0.6 \mathrm{mmol} / \mathrm{L})$ and LDL cholesterol $(0.5 \mathrm{mmol} / \mathrm{L})$ concentrations after 12 months of treatment was reported in patients treated with pasireotide, and achieving a full control of cortisol secretion, although an improvement in lipid profile was also found in patients uncontrolled under pasireotide. ${ }^{55}$

\section{General considerations on metabolic syndrome}

Transient or persistent adrenal insufficiency was described in between $40 \%$ and $100 \%$ of patients with Cushing's syndrome assessed for metabolic parameters after surgical remission. ${ }^{36,38,40}$ Since glucocorticoid replacement treatment has been associated with an unfavourable metabolic profile in patients with hypopituitarism, ${ }^{62}$ glucocorticoid over-replacement after surgical remission 
might have a role in the persistence of metabolic disorders in patients with Cushing's syndrome. Different postoperative hormonal deficiencies or their replacement might play a part in the abnormal metabolic profile seen after remission from Cushing's syndrome, especially Cushing's disease. Taking into account the central role of insulin resistance in the pathogenesis of metabolic syndrome, the use of insulin sensitisers might be useful in patients with disorders of glucose metabolism in ameliorating the metabolic profile during both the active and the remission phases of Cushing's syndrome. ${ }^{63}$

\section{Cardiovascular disease Overview}

Cardiovascular disease is commonly reported as the main cause of death in patients with Cushing's syndrome. Indeed the increased mortality has traditionally been attributed to chronic damage from hypertension, in particular vascular atherosclerosis and cardiac remodelling and dysfunction..$^{37,64,65}$ However, in the active phase, or in the early postoperative period, hypokalaemia and venous thromboembolism are also important contributors. ${ }^{66}$ A range of changes in metabolic, haemodynamic, and coagulatory pathways induced by glucocorticoid excess are responsible for hypertension as well as vascular and cardiac disease, and thrombosis diathesis (figure 3).

\section{Systemic arterial hypertension}

Hypertension is a very common clinical feature of Cushing's syndrome, occurring in 25-93\% of patients. ${ }^{16,18,21-24,26-28,36-40,42,44,56,65,67-70}$ See appendix for a systematic analysis of the studies on hypertension in Cushing's syndrome. Most studies showed that systolic and diastolic blood pressure was raised to a similar extent in these patients, with loss of the physiological nocturnal decrease being an early feature. ${ }^{64,71}$ Although the duration of uncontrolled hypercortisolism seems to correlate with development of hypertension in adults, ${ }^{64}$ half of paediatric patients with Cushing's syndrome (whose time to diagnosis is shorter) ${ }^{72}$ still develop hypertension. ${ }^{64}$ The prevalence of hypertension is similar in male and female patients and among the various types of Cushing's syndrome. ${ }^{37,45,56}$ The main mechanisms involved in the pathogenesis of hypertension in Cushing's syndrome include the modification induced by glucocorticoid excess in the renin-angiotensin system, the mineralocorticoid activity, the sympathetic nervous system, and the vasoregulatory system (panel 3).

The ideal treatment of Cushing's syndrome-related hypertension is the surgical removal of the tumour responsible for the disease. Remission from hypercortisolism can improve hypertension but it does not always normalise. In fact, the presence of hypertension has been reported in $25-54 \%$ of patients in remission from Cushing's syndrome. ${ }^{36,38-40,65,67}$ Adrenal-directed drugs can worsen hypertension by increasing cortisol and aldosterone precursors with mineralocorticoid activity;

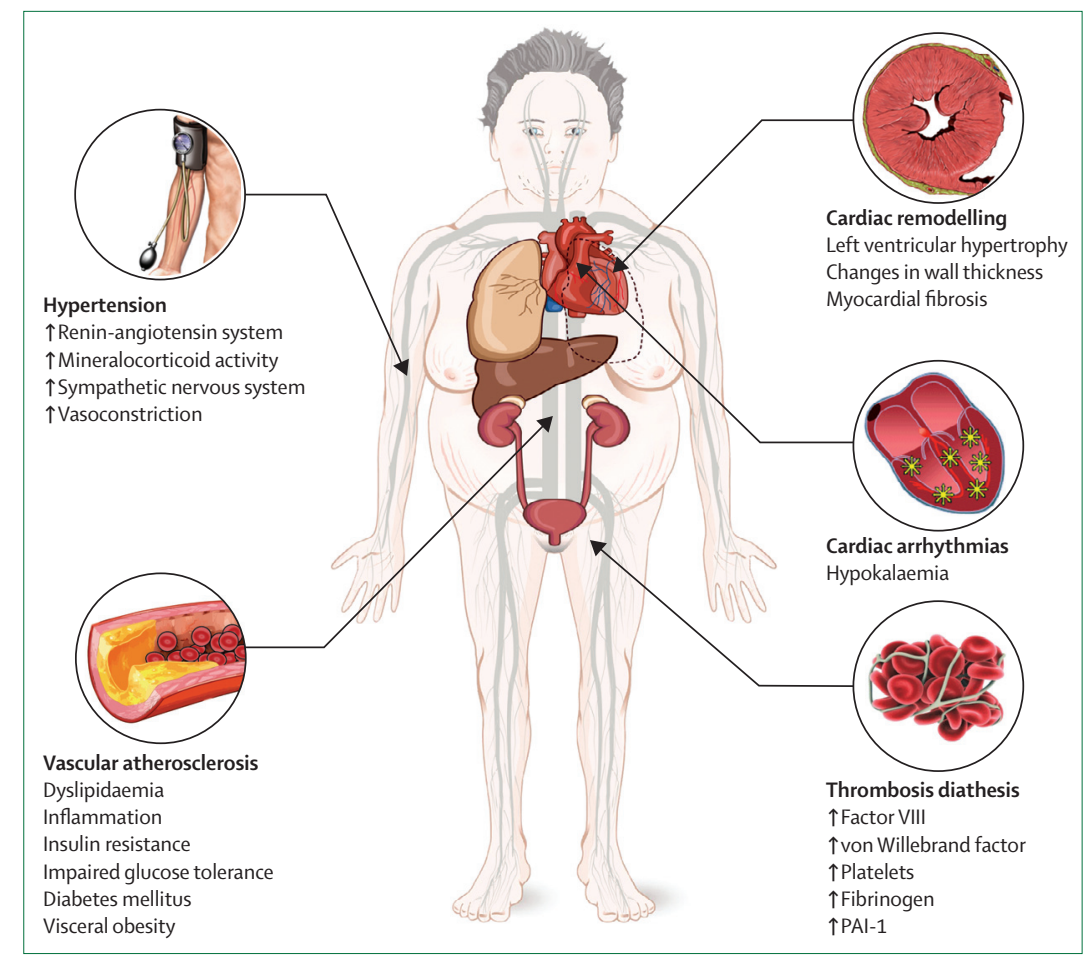

Figure 3: Main pathogenic mechanisms contributing to cardiovascular disease in Cushing's syndrome Figure shows the tissue abnormalities seen in affected organs, the main pathogenic mechanisms underlying cardiovascular disease in Cushing's syndrome, and the consequent clinical complications. $\uparrow$ indicates increased $\downarrow$ indicates decreased. Hypertension, vascular remodelling, and atherosclerosis result from the interplay between several mechanisms regulating plasma volume, peripheral vascular resistance, and cardiac output, all of which are increased in Cushing's syndrome. The mechanisms involved include the renin-angiotensin system, mineralocorticoid activity, the sympathetic nervous system, and the vasoregulatory system. Hypokalaemia increases the risk of malignant ventricular arrhythmias. The pro-inflammatory status, altered angiogenesis, hyperinsulinaemia, and dyslipidaemia all contribute to increased intima-media thickness, development of concentric left-ventricular hypertrophy, impaired diastolic filling, and myocardial fibrosis. A remarkable rise in concentrations of factor VIII, von Willebrand factor, and platelets, and a shortening of the activated partial thromboplastin time, are frequently noted in Cushing's syndrome. PAI-1=plasminogen activator inhibitor type 1.

these effects have been described for the 11ß-hydroxylase inhibitors, metyrapone ${ }^{4}$ and osilodrostat (LCI699). ${ }^{73}$ Mifepristone reduced blood pressure in about half of treated patients, although in some patients, hypertension and hypokalaemia worsened because of excessive cortisol concentrations, which saturate 11ß-hydroxysteroid dehydrogenase type 2 (11 $\beta$-HSD2), an enzyme that converts cortisol into cortisone, resulting in activation of mineralocorticoid receptors. This situation requires concurrent treatment with potassium and spironolactone. $^{74}$ Cabergoline and pasireotide improve hypertension, irrespective of any concomitant antihypertensive drugs. ${ }^{46,55}$ However, pharmacological treatment for hypertension is often required (see appendix for flow-chart of proposed treatment of hypertension in Cushing's syndrome).

\section{Cardiac and vascular damage}

Cushing's syndrome is associated with an increased risk for myocardial infarction (hazard ratio [HR] 2.1, 95\% CI $0 \cdot 5-8 \cdot 6)$ and cardiac failure $(6 \cdot 0,2 \cdot 1-17 \cdot 1) \cdot{ }^{28}$ Concentric 
Panel 3: Mechanisms involved in the pathogenesis of hypertension in Cushing's syndrome ${ }^{64}$

Increased activity or concentrations

Renin-angiotensin system

- Angiotensinogen

- Pressor response to angiotensin II

- Angiotension II type $1 \mathrm{~A}$ receptor

Mineralocorticoid activity

- $11 \beta$-hydroxysteroid dehydrogenase type 2 saturation

- Plasma volume

Sympathetic nervous system

- Sensitivity to $\beta$-receptor agonists

Vasoregulatory system

- Circulating endothelin 1

- Erythropoietin in patients treated for Cushing's syndrome

- Circulating atrial natriuretic peptide

- Urinary kininase I, II, neutral endopeptidase

\section{Decreased activity}

Vasoregulatory system

- Atrial natriuretic peptide activity

- Nitric oxide pathway

- Urinary prostaglandin E2

- Prostacyclin 12 production

- Urinary kallikrein

left ventricle hypertrophy, together with a decrease in systolic strain and impairment in diastolic filling caused by an abnormal relaxation pattern, has been described in Cushing's syndrome..$^{67,70,75}$ Patients with Cushing's syndrome develop a more pronounced left ventricle hypertrophy than do hypertensive controls, suggesting that hypertension is not the only factor determining cardiac hypertrophy and consequent dysfunction. ${ }^{67}$ Increased myocardial fibrosis - caused by an enhanced responsiveness to angiotensin II and activation of the mineralocorticoid receptor in direct response to cortisol excess- has been proposed as an underlying cause of the cardiac damage. ${ }^{76, \pi}$ Myocardial fibrosis could exacerbate the effects of hypokalaemia on QT interval prolongation seen in patients with Cushing's syndrome; ${ }^{78}$ this effect is more evident in male than female patients, suggesting that the testosterone deficiency observed in men with hypercortisolism could be a contributing factor. ${ }^{78}$

Vascular atherosclerosis is a common feature of Cushing's syndrome. An increased prevalence of well-defined vascular wall plaques has been reported in patients with Cushing's syndrome. ${ }^{36,42}$ The intima-media thickness of both carotid and aortic arteries can be increased in Cushing's syndrome. ${ }^{36,42}$ A major role of insulin resistance in the development of vascular damage has been suggested, but different factors such as glucocorticoid-induced endothelial dysfunction, enhancement of arterial stiffness, thrombosis diathesis, increase in homocysteine, and decrease in taurine concentrations could also have a role. ${ }^{30,42,79}$ The vascular damage is probably the cause of the increased risk of stroke (HR 4.5, 95\% CI 1.8-11.1) associated with Cushing's syndrome. ${ }^{28}$

The described cardiovascular changes are only partly reversible after successful treatment. Myocardial fibrosis and cardiac abnormalities showed a partial improvement after successful treatment of Cushing's syndrome, ${ }^{80}$ whereas vascular intima media thickness remained increased compared with controls for up to 5 years. ${ }^{36,40}$ In patients with active Cushing's syndrome, intima media thickness was closely correlated to visceral adiposity and insulin resistance, suggesting a causative link; however, the loss of such correlation after remission suggests a role for additional factors such as persistence of hypertension or inflammation. ${ }^{36,40,57}$

Cardiovascular morbidity was similar in glucocorticoidtreated ACTH-insufficient and ACTH-sufficient patients with hypopituitarism (stroke in $2.1 \%$ of patients and coronary heart disease in $4.3 \%$ of patients in both groups).$^{62}$ However, whether glucocorticoid overexposure in patients with adrenal insufficiency after disease remission contributes to the persistence of cardiovascular disease requires further investigation.

\section{Thrombosis diathesis}

Cushing's syndrome is associated with a more than ten-fold increased risk of venous thromboembolism compared with people without Cushing's syndrome. ${ }^{36,40,81,82}$ Thromboembolic events have been reported in $6-20 \%$ of patients with Cushing's syndrome, particularly in the early postoperative period. ${ }^{83}$ The increased cardiovascular mortality in Cushing's syndrome, initially attributed predominantly to hypertension, is now also attributed to an increased thrombotic risk. ${ }^{66,81,82}$ Glucocorticoids are important physiological regulators of haemostasis and act on bone marrow, vessels, and liver. ${ }^{81}$ However, many studies have not discriminated between the effects of glucocorticoids per se, and the secondary effects of obesity and organ damage. ${ }^{66}$ Many alterations of coagulation and fibrinolysis occur in Cushing's syndrome. ${ }^{66}$ A remarkable rise in factor VIII, fibrinogen, and von Willebrand factor levels, and a shortening of the activated partial thromboplastin time, are the hallmarks of the haemostatic alterations in Cushing's syndrome, accompanied by a rise in the number of platelets, thromboxane B2, and thrombin-antithrombin complexes (table). ${ }^{6,82}$ Increased activity of endogenous coagulation inhibitors has also been reported, probably as a compensatory mechanism for the increased coagulatory factors. Impaired fibrinolytic capacity, which is reflected by substantially increased levels of plasminogen activator inhibitor-1, has been described. ${ }^{66,82}$ Haemostatic abnormalities seem to improve 1 year after remission, although they do not fully normalise. ${ }^{81,82}$ In addition to an acute direct effect of glucocorticoids, a more sustained indirect effect mediated by chronic endothelial damage and atherosclerosis is probably involved. ${ }^{66}$ 
Successful pharmacological treatment does not seem to improve the hypercoagulable state, and this might be partly explained by persistence of the metabolic syndrome. ${ }^{66,82}$ In a retrospective analysis, postoperative antithrombotic prophylaxis reduced morbidity and mortality caused by thromboembolic events from $20 \%$ and $10 \%$ to $6 \%$ and $0.4 \%$, respectively. ${ }^{83}$ Routine antithrombotic prophylaxis has also been recommended during inferior petrosal sinus sampling, in addition to the immediate postoperative period after pituitary or adrenal surgery. ${ }^{6,66}$ More intensive routine antithrombotic measures (adequate anticoagulant treatment and screening of haemostatic parameters) have been advocated for surgical prophylaxis in patients with Cushing's syndrome. ${ }^{11,66}$ Since platelet activation has also been reported, a chronic anti-aggregation therapy could be considered. ${ }^{66}$

\section{Hypokalaemia}

Hypokalaemia affects more than half of patients with ectopic Cushing's syndrome, ${ }^{69}$ but it can occur in any patient with severe Cushing's syndrome. No difference was noted in the development of hypokalaemia in male and female patients with Cushing's syndrome. ${ }^{45}$ Indeed, a significant correlation was found between daily urinary cortisol excretion and severity of hypokalaemia. ${ }^{69}$ In Cushing's syndrome, hypokalaemia causes a metabolic alkalosis that is not associated with chlorine depletion and is therefore unresponsive to saline administration. Hypokalaemia can be detected with the typical electrocardiogram signs, which include QT interval prolongation, and should be considered when starting pharmacological treatments affecting the QT interval. With worsening hypokalaemia, supraventricular tachyarrhythmias and life-threatening ventricular arrhythmias might occur. Hypokalaemia is often associated with hypomagnesaemia, which increases the risk of malignant ventricular arrhythmias. ${ }^{84}$ Hypokalaemia has been attributed to excessive glucocorticoids saturating $11 \beta$-HSD2, leading to inappropriate activation of the mineralocorticoid receptor. ${ }^{85}$ Worsening of hypokalaemia has been reported with adrenal-directed drugs that can increase cortisol precursors with mineralocorticoid activity, and also with mifepristone. ${ }^{74}$ Oral or parenteral correction of hypokalaemia and concomitant hypomagnesaemia is advocated.

\section{Immunological disorders Pathogenesis}

Cushing's syndrome is associated with immunosuppression during the active phase of the disease, which is responsible for the susceptibility to infections, and might be associated with an immune rebound after disease remission, which is responsible for the relatively frequent development or exacerbation of autoimmune diseases. ${ }^{57,86}$ Glucocorticoid excess induces substantial changes in the entire immune system (figure 4). Glucocorticoid excess interferes with host defence

\begin{tabular}{|c|c|c|}
\hline & $\begin{array}{l}\text { Coagulation phase } \\
\text { during active phase }\end{array}$ & $\begin{array}{l}\text { Coagulation phase } \\
\text { during remission phase }\end{array}$ \\
\hline \multicolumn{3}{|l|}{ Platelets } \\
\hline Platelet count & $=$ or $\uparrow$ & NA \\
\hline Thromboxane B2 & $\uparrow$ & NA \\
\hline von Willebrand factor & $=$ or $\uparrow$ & $=$ or $\uparrow$ \\
\hline \multicolumn{3}{|l|}{ Coagulation cascade } \\
\hline aPTT & $=$ or $\downarrow$ & $=$ or $\downarrow$ \\
\hline Factor VIII & $=$ or $\uparrow$ & $=$ or $\uparrow$ \\
\hline $\begin{array}{l}\text { Thrombin-antithrombin } \\
\text { complexes }\end{array}$ & $\uparrow$ & NA \\
\hline Fibrinogen & $=$ or $\uparrow$ & $\uparrow$ \\
\hline \multicolumn{3}{|l|}{ Regulators of haemostasis } \\
\hline Protein C & $=$ or $\uparrow$ & $\uparrow$ \\
\hline Protein S & $=$ or $\uparrow$ & $\uparrow$ \\
\hline Antithrombin III & $\uparrow$ & $=$ \\
\hline \multicolumn{3}{|l|}{ Fibrinolysis } \\
\hline PAI-1 & $=$ or $\uparrow$ & $=$ or $\uparrow$ \\
\hline \multicolumn{3}{|c|}{$\begin{array}{l}\text { Table shows direction of association in reported studies, as reported in the } \\
\text { scientific literature. } \uparrow \text { indicates significantly increased; } \downarrow \text { indicates significantly } \\
\text { decreased; =indicates equal (compared with healthy controls). aPTT=activated } \\
\text { partial thromboplastin time. NA=not applicable. PAI- } 1=\text { plasminogen activator } \\
\text { inhibitor type } 1 .\end{array}$} \\
\hline $\begin{array}{l}\text { Table: Haemostasis disord } \\
\text { during active and remissi }\end{array}$ & $\begin{array}{l}\text { ders in patients with } C \\
\text { ion phases compared } v\end{array}$ & $\begin{array}{l}\text { Ushing's syndrome } \\
\text { with controls }{ }^{66,81-83}\end{array}$ \\
\hline
\end{tabular}

systems through hyperglycaemia and vascular damage, directly or indirectly. ${ }^{86}$ Glucocorticoids affect both the cellular and humoral components of the innate immune system. Indeed, glucocorticoids impair neutrophil function, eosinophil and monocyte production, macrophage maturation, and natural killer action, substantially altering the cellular response to infection. ${ }^{86}$ Humoral components of the innate immune system are also influenced by glucocorticoids, affecting inhibition of lymphocyte proliferation and downregulation of relevant pro-inflammatory cytokines and complement components. ${ }^{86}$ Moreover, glucocorticoids compromise aspects of the adaptive response through inhibition of antigen-presenting dendritic cells, affecting T-cell maturation, and limiting B-cell development and proliferation. ${ }^{86}$ Glucocorticoids influence the production and action of T-helper (Th) lymphocyte subclasses Th1 and Th2, which are components of adaptive immunity; Th1 cells are the primary agents of cellular immunity, whereas Th2 cells are modulators of humoral immunity. ${ }^{86}$ Th1 cells producing interferon $\gamma$, interleukin 2 , and tumour necrosis factor $\beta$ induce $B$ cells to produce opsonising and complement-fixing antibodies of the IgG class, whereas Th2 cells producing interleukins 4, 5, 6, 10 , and 13 induce B cells to produce immunoglobulins, particularly the IgE class. Glucocorticoids suppress Th1 responses, with a consequent increase in susceptibility to intracellular and opportunistic infections, and promote Th2 responses, which could explain the possible development of certain autoimmune diseases 


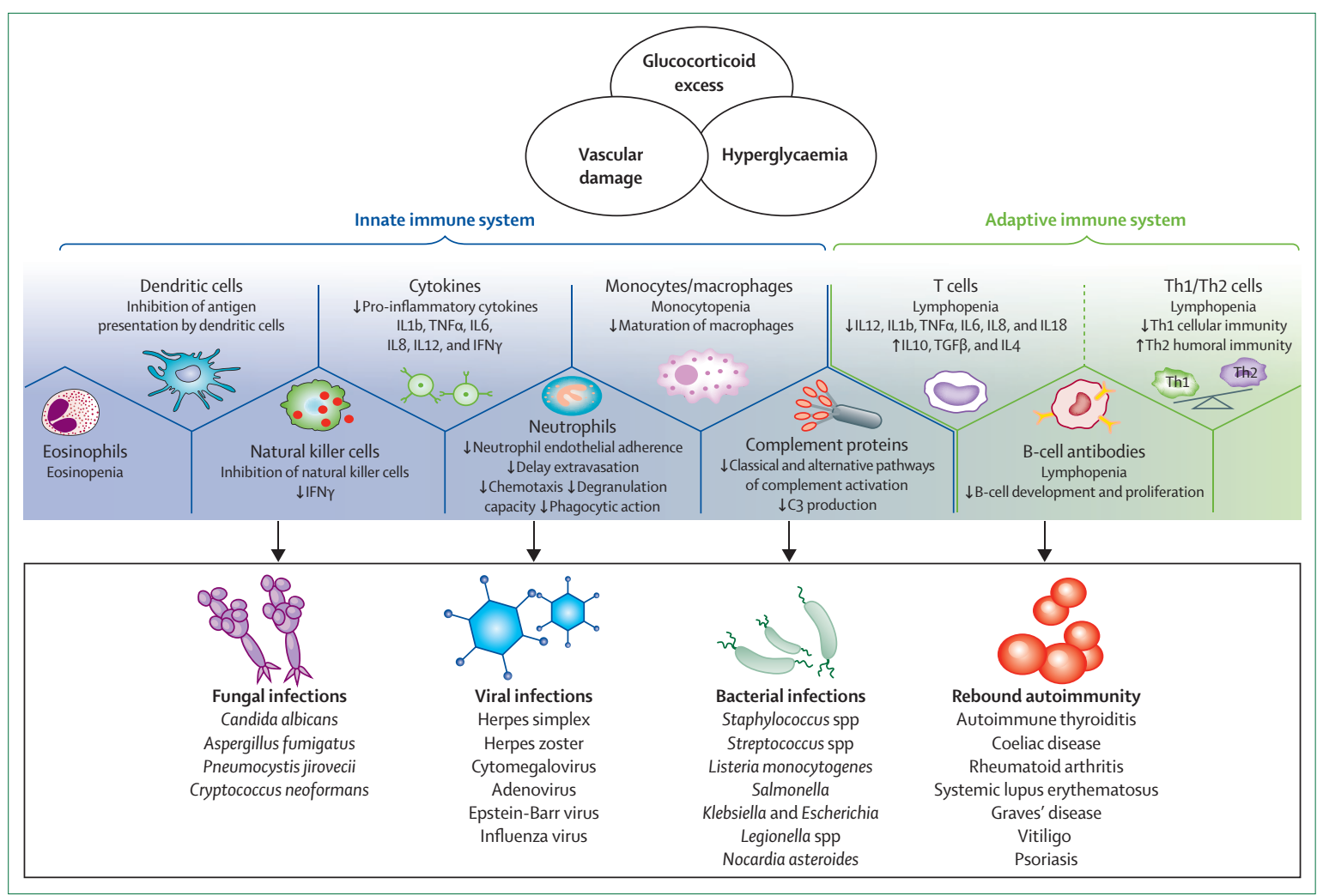

Figure 4: Main pathogenic mechanisms and clinical consequences of the immune disorders associated with Cushing's syndrome

Glucocorticoid excess, together with hyperglycaemia and vascular damage, has detrimental effects on the innate and adaptive immune system. Main mechanisms underlying these immunological alterations range from various degrees of immune suppression exerted on lymphocytes, antigen-presenting dendritic cells, and natural killer cells, to a relative imbalance between Th1 and Th2 humoral immunity. The clinical consequences are an increased susceptibility to infections (ie, fungal, viral, and bacterial) during the active phase and rebound autoimmunity during the remission phase of Cushing's syndrome. $\uparrow$ indicates increased; $\downarrow$ indicates decreased. Th=T-helper. IFN $\gamma=$ interferon $\gamma$. IL=interleukin. TNF $\alpha=$ tumour necrosis factor $\alpha$. TGF $\beta=$ transforming growth factor $\beta$. C3=complement component 3 .

in patients with active Cushing's syndrome. ${ }^{86,87}$ The Th1/ Th2 imbalance might also contribute to the uncontrolled immune response and rebound autoimmunity during the remission phase of the disease. New-onset and exacerbations of autoimmune disease have been described after successful treatment of Cushing's syndrome. ${ }^{57}$ The mechanism underlying the development of autoimmunity in patients with Cushing's syndrome after their cure has not been completely clarified yet and requires further study. These findings suggest that the effects of glucocorticoids on the immune system are far more complex than a universal immunosuppression.

\section{Infectious diseases}

The impairment of immune function associated with active Cushing's syndrome predisposes patients to infectious diseases, especially opportunistic infections. See appendix for a systematic analysis of the studies on infectious diseases in Cushing's syndrome. The high frequency of opportunistic infections in Cushing's syndrome is linked to increased mortality; it is related to the time of exposure to hypercortisolism, and is associated with severe forms of Cushing's syndrome. ${ }^{86}$ In a population-based cohort study, the prevalence of infections was increased in patients with Cushing's syndrome before diagnosis (HR 2.4, 95\% CI 1.0-5.9), similarly between pituitary and adrenal Cushing's syndrome, being higher in the 1-year period before surgery (HR 5 · , 2 2-14.4) and peaking in the 3 -month period after surgery (HR 38.2, 95\% CI 16.9-86.1), suggesting a cumulative effect of hypercortisolism exacerbated by surgery. ${ }^{28}$ A few studies primarily addressed the epidemiology of infections in Cushing's syndrome, reporting a prevalence of $21-51 \%$, 88 ${ }^{91}$ with a tendency towards a higher prevalence in ectopic Cushing's syndrome $(23-51 \%)^{88-90}$ than in Cushing's disease $(21 \%) .{ }^{91}$ The susceptibility to invasive infections seems to be independent of the type of Cushing's syndrome, but is correlated with the severity of hypercortisolism. ${ }^{88,89,92}$ Because of the masking effect caused by the anti-inflammatory action of glucocorticoids, total leucocyte counts or temperature are not reliable indicators of active infection, and the absolute concentration of cortisol is the best predictor of severe infection in patients with Cushing's syndrome. ${ }^{89}$

The increased risk of infection associated with severe cortisol excess applies to virtually any microbial pathogen, ${ }^{86,93}$ but some infections are more common 
than others. The most frequent infections are community-acquired and nosocomial bacterial infections ${ }^{86}$ caused by Gram-positive (Staphylococcus spp, Streptococcus spp, Listeria spp, and Nocardia spp) and Gram-negative (enterobacteria and Legionella spp) organisms. ${ }^{94}$ Fungal infections are also frequent, with the most typical fungal pathogens being Candida spp, Aspergillus spp, and Cryptococcus spp as well as Pneumocystis jirovecii. ${ }^{86,93}$ Invasive fungal infections should be suspected in patients with Cushing's syndrome with early signs and symptoms of infection that are unresponsive to broad-spectrum antibiotics. ${ }^{95}$ Conversely, when an opportunistic infection occurs in the presence of persistent severe hypokalaemia, Cushing's syndrome should be considered, although the results of testing the hypothalamic-pituitary-adrenal axis during systemic illness can be difficult to interpret. ${ }^{96}$ Cushing's syndrome is frequently associated with severe and persistent forms of common viral infections, ${ }^{86}$ including herpes simplex, herpes zoster, and cytomegalovirus. Different viruses, such as adenovirus, influenza virus, and Epstein-Barr virus, can also have more severe and protracted clinical courses in patients with Cushing's syndrome than in people without Cushing's syndrome. ${ }^{86}$ Control of hypercortisolism can often uncover an otherwise clinically silent opportunistic infection, due to the anti-inflammatory effects of cortisol suppressing the signs and symptoms of infection. ${ }^{97}$ Primary prophylaxis for Pneumocystis jirovecii infection with co-trimoxazole (or dapsone for patients with allergy to co-trimoxazole) has been proposed in all patients with very high concentrations of circulating cortisol. . $^{11,92}$ Nevertheless, successful treatment of opportunistic infections often depends on the rapidity in normalising cortisol secretion.

\section{Autoimmune diseases}

A few studies have investigated the prevalence of autoimmune diseases in patients with Cushing's syndrome, reporting a prevalence of a range of autoimmune disorders of $0-20 \%$ during the active phase and a higher prevalence of up to $60 \%$ during the remission phase of the disease. ${ }^{98-101}$ See appendix for a systematic analysis of the studies on autoimmune diseases in Cushing's syndrome. Clinicians treating patients with Cushing's syndrome need to be aware of this possible treatment outcome. The range of autoimmune disorders is wide, with thyroid autoimmunity the most commonly reported (prevalence 10-60\%). ${ }^{100}$ Coeliac disease can occur with a subtle presentation, or be associated weight loss; however, the weight loss observed in patients with coeliac disease can be wrongly attributed to the weight loss expected in patients in remission from hypercortisolism, thus obfuscating the diagnosis of coeliac disease. Testing patients with Cushing's syndrome for autoimmune thyroiditis and coeliac disease is suggested, particularly during the 6 months after
Cushing's syndrome remission. ${ }^{100}$ Thymic hyperplasia might develop three or more weeks after remission from Cushing's syndrome, ${ }^{102}$ but it may spontaneously regress. The differential diagnosis between thymic hyperplasia after control of hypercortisolism and a thymic source of ectopic ACTH production can be challenging.

\section{Musculoskeletal diseases \\ Skeletal damage}

An impairment of bone status has been described in $64-100 \%$ of patients with Cushing's syndrome; in particular, osteopenia occurs in $40-78 \%$, osteoporosis in $22-57 \%$, and skeletal fractures in $11-76 \%$ of patients. ${ }^{24,56,103-114}$ See appendix for a systematic analysis of the studies on skeletal diseases in Cushing's syndrome. Bone mineral density (BMD) is reduced in patients with Cushing's syndrome. ${ }^{103,104,106,108,110,113,115-118}$ An increased incidence of low-energy fractures occurs, particularly within the 2-3 years before diagnosis and treatment, ${ }^{28,19}$ suggesting that prompt recognition and management of Cushing's syndrome are essential to reduce skeletal complications. The prevalence of osteoporosis is higher in patients with adrenal Cushing's syndrome than in those with pituitary Cushing's syndrome. ${ }^{106,107}$ BMD appears to be lower and vertebral fractures more prevalent in ectopic than in pituitary Cushing's syndrome. ${ }^{56,113}$ These data suggest that adrenal androgen suppression or disease severity could negatively affect bone status in Cushing's syndrome, but this notion remains controversial, since some studies did not find differences in bone disease frequency and severity in the different types of Cushing's syndrome..$^{5,113,115,120}$ Male patients have a higher prevalence of osteoporosis (47\% vs $32 \%, \mathrm{p}<0 \cdot 05 ;{ }^{45}$ and $40 \%$ vs $20 \%, \mathrm{p}<0 \cdot 05^{56}$ ) and vertebral fractures $(52 \% \text { vs } 18 \% \text {; } \mathrm{p}<0 \cdot 001)^{56}$ than female patients, suggesting that testosterone deficiency could negatively affect bone status in Cushing's syndrome. Amenorrhoeic and eumenorrhoeic women with Cushing's syndrome have similar BMD values and fracture prevalence, ${ }^{108,13}$ suggesting that the harmful effects of glucocorticoids overcome oestrogenic bone protection in Cushing's syndrome.

Glucocorticoid excess affects bone status through a number of different mechanisms (figure 5). Glucocorticoids exert their effects on bone metabolism directly through uncoupling bone turnover, and indirectly through alteration of calcium homoeostasis and impairment of pituitary hormone secretion. Catabolic effects on muscles might also have a role, since these effects lead to muscle weakness and disuse, diminishing the muscle trophic effect on bone. ${ }^{121-123}$ Glucocorticoids induce an imbalance between bone formation and bone reabsorption; they inhibit osteoblast differentiation and function, promote osteoblast and osteocyte apoptosis via the activation of caspase 3, and prolong osteoclast lifespan. Inhibition of osteoblast differentiation has been attributed to inactivation of the Wnt/ $\beta$-catenin signalling pathway and induction of nuclear factors of the CCAAT-enhancer-binding protein 


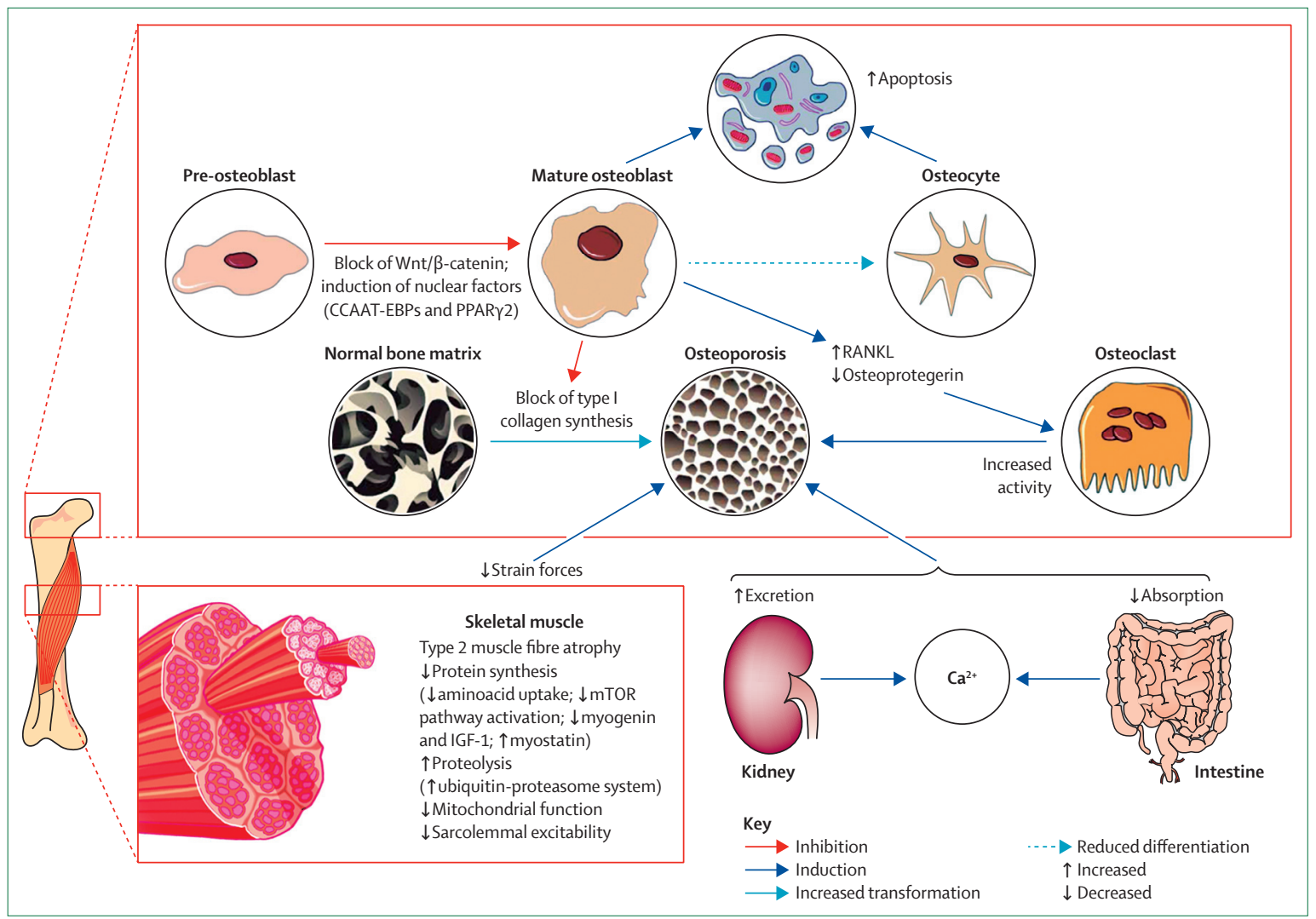

Figure 5: Main pathogenic mechanisms underlying the alteration of skeletal structure and function in Cushing's syndrome

The main pathogenic mechanisms directly related to bone are included in the main box. Circled images represent the main cell types or bone components that have a role in the alteration of skeletal structure and function in patients with Cushing's syndrome. The main pathogenic mechanisms indirectly related to bone are represented outside the main box. $\mathrm{Ca}^{2+}=$ calcium. $C$ CAAT-EBP=enhancer-binding protein family. IGF-1=insulin-like growth factor 1 . $\mathrm{mTOR}=$ mechanistic target of rapamycin. PPAR $\gamma 2=$ peroxisome proliferator-activated receptor $\gamma$ type 2 . RANKL=the receptor activator of nuclear factor kappa-B ligand.

family and peroxisome proliferator-activated receptor $\gamma$ type 2, whereas blockade of type I collagen synthesis by differentiated osteoblasts has been shown to reduce the bone matrix available for mineralisation. ${ }^{121}$ The decreased number of osteocytes induces bone microarchitectural alterations, reducing bone surface turnover in response to mechanical forces. ${ }^{121}$ Glucocorticoids also increase the receptor activator of nuclear factor kappa-B ligand and decrease osteoprotegerin production in osteoblasts, promoting increased osteoclastic activity. ${ }^{121,123}$ Finally, differential sensitivity of bone cells to glucocorticoid action has been described: patients with the N363S polymorphism in glucocorticoid receptors ${ }^{121,123}$ and higher 11ß-HSD1 activity $^{121}$ could have a higher likelihood of glucocorticoidinduced bone damage.

Surgical remission improved BMD in most

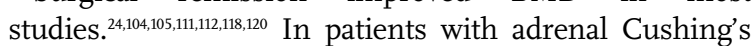
syndrome, an improvement in BMD at the lumbar spine but not at the femoral neck was noted 3 months after hypercortisolism remission. ${ }^{105}$ In a mixed population including patients with pituitary and adrenal Cushing's syndrome, BMD improved in both lumbar spine and femoral neck, but only after follow-up longer than
6 months. ${ }^{111}$ Several prospective studies assessing bone status in patients followed up for at least 1 year after remission from hypercortisolism reported a progressive improvement in BMD, ${ }^{104,105,111,112,118,120}$ generally more slowly in the femoral neck than the lumbar spine. ${ }^{105,118,120}$ In a group of patients with Cushing's disease, lumbar spine BMD was still lower than in controls 2 years after remission, ${ }^{104}$ whereas lumbar spine and femoral neck BMD normalised in patients with Cushing's syndrome after a mean follow-up of 71 months. ${ }^{118}$ These data highlight the potential reversibility of bone damage with control of hypercortisolism, although the time to complete bone recovery is relatively long and variable. A greater increase in BMD after remission has been reported in male than female patients. ${ }^{120}$ Notably, the duration of glucocorticoid replacement was negatively correlated with lumbar spine BMD in women with Cushing's syndrome in long-term surgical remission, ${ }^{115}$ suggesting that several factors, including sex and glucocorticoid over-replacement might affect the time to bone recovery.

Few data regarding the effects of pharmacological treatment on bone disease are available. Despite the lowering of cortisol, no significant improvement in BMD 
was recorded in two small cohorts of patients with Cushing's disease treated with ketoconazole for up to 100 months, ${ }^{116,124}$ whereas amelioration was reported in three patients treated for more than 36 months. ${ }^{47}$ A better outcome after 6 months has been reported in patients with Cushing's syndrome treated with ketoconazole plus alendronate. ${ }^{116}$ Recommendations for the treatment of osteoporosis induced by exogenous hypercortisolism can be only partly translated to patients with endogenous Cushing's syndrome; therefore, specific guidelines for these patients are still needed. Stratification of patients into two treatment subgroups-according to the cause of Cushing's syndrome, gonadal status, age, presence of fractures, and expected time for hypercortisolism resolution-has recently been suggested. ${ }^{125}$ These subgroups are patients with less severe bone damage, needing only supplementation with calcium and vitamin D (eg, those not presenting with prevalent fractures, premenopausal women, and men younger than 50 years), and patients with more severe bone damage requiring more aggressive treatment such as bone active therapy with bisphosphonates, teriparatide, and denosumab (eg, those with severe hypercortisolism, prevalent hip or vertebral fractures, and those older than 70 years). ${ }^{125}$ Although active bone therapy might be effective in endogenous Cushing's syndrome, further investigation is needed to make specific treatment recommendations.

\section{Muscle damage}

Myopathy has been frequently described in patients with Cushing's syndrome, with a prevalence ranging from $42 \%$ to $83 \%$. $^{1,24,45,56}$ Cushing's syndrome myopathy more severely affects the proximal part of lower limbs, ${ }^{126}$ and can take months to years to resolve. The prevalence of myopathy is slightly higher in ectopic than in adrenal Cushing's syndrome ${ }^{56}$ and significantly higher in male than female patients. ${ }^{45}$

Glucocorticoid excess affects the structure and function of skeletal muscle through different mechanisms (figure 5). Glucocorticoids induce type 2 muscle fibre atrophy through both anti-anabolic and catabolic actions. ${ }^{126,127}$ Glucocorticoids impair protein synthesis in muscle by inhibiting aminoacid uptake, repressing the insulin-like growth factor 1 (IGF-1)-activated mechanistic target of rapamycin pathway, and inhibiting myogenesis by downregulating myogenin. ${ }^{127}$ Glucocorticoids also stimulate proteolysis particularly through the ubiquitinproteosome system. ${ }^{127}$ The alteration of local growth factors such as the inhibition of IGF-1, the stimulation of myostatin, and the impairment in mitochondrial function and sarcolemmal excitability also contribute to glucocorticoid-induced myopathy. ${ }^{126,127}$

Musculoskeletal pain and acute bilateral carpal tunnel syndrome have been described as a result of cortisol withdrawal syndrome after surgical remission. ${ }^{128}$ The reversibility of myopathy after surgical or pharmacological remission of Cushing's syndrome, and the role of preventive interventions such as the use of anabolic factors or physical activity programmes, need further investigation. ${ }^{126}$

\section{Neuropsychiatric diseases}

Neuropsychiatric diseases are severe comorbidities of Cushing's syndrome, in both the active and remission phases, ${ }^{6,129,130}$ this topic is reviewed in detail in a recent review of the scientific literature. ${ }^{129}$ The most common psychiatric diseases in Cushing's syndrome are major depression (prevalence 50-81\%), anxiety (66\%), and bipolar disorders (30\%). ${ }^{129}$ Chronic brain exposure to cortisol excess causes deep structural and functional changes in various cerebral areas that are rich in glucocorticoid receptors, particularly the hippocampus, amygdala, and prefrontal cortex, including the limbic system, all of which are fundamental regions for emotional and cognitive functions. ${ }^{131-133}$

Some studies have reported an improvement in neuropsychiatric disorders after disease remission obtained by either surgery or pharmacological treatment, but resolution of hypercortisolism is not always followed by complete recovery, suggesting irreversible adverse effects on the central nervous system..$^{129}$ The persistence or, rarely, the worsening of depression or anxiety after disease remission might also depend on adrenal insufficiency and frequent overexposure to glucocorticoid replacement therapy. ${ }^{134}$ Besides normalisation of cortisol secretion, psychotherapeutic strategies, such as cognitive behavioural therapies and psychotropic drugs, including antidepressant agents (eg, tricyclic agents and selective serotonin reuptake inhibitors), can be useful in treating psychiatric disorders associated with Cushing's syndrome. ${ }^{130}$ Benzodiazepines can help in cases of severe anxiety. ${ }^{130}$ These data highlight the importance of long-term follow-up and careful periodic investigation of neuropsychiatric complications associated with Cushing's syndrome. ${ }^{129}$

\section{Reproductive and sexual disorders General considerations}

Reproductive and sexual disorders in Cushing's syndrome are very common. ${ }^{1,2,4}$ Decreased libido (24-90\%), hypogonadism in men (50-75\%), and menstrual irregularity in women (43-80\%) are the most common clinical features, the latter more frequent in patients with pituitary than in those with adrenal Cushing's syndrome..$^{2,24,37,56,135-138}$ Fertility is seriously impaired in patients with Cushing's syndrome, but this might also be a consequence of the reduced libido and lower frequency of sexual activity. Reports that women with Cushing's syndrome often do not seek pregnancy because of their serious clinical conditions suggest that the physical effects of the syndrome on reproduction are underestimated. ${ }^{139}$ In Cushing's syndrome, the hypothalamic-pituitary-gonadal axis can be affected at different levels. The alteration of the hypothalamus-pituitarygonadal axis, together with several metabolic alterations, are responsible for the impairment of fertility and 


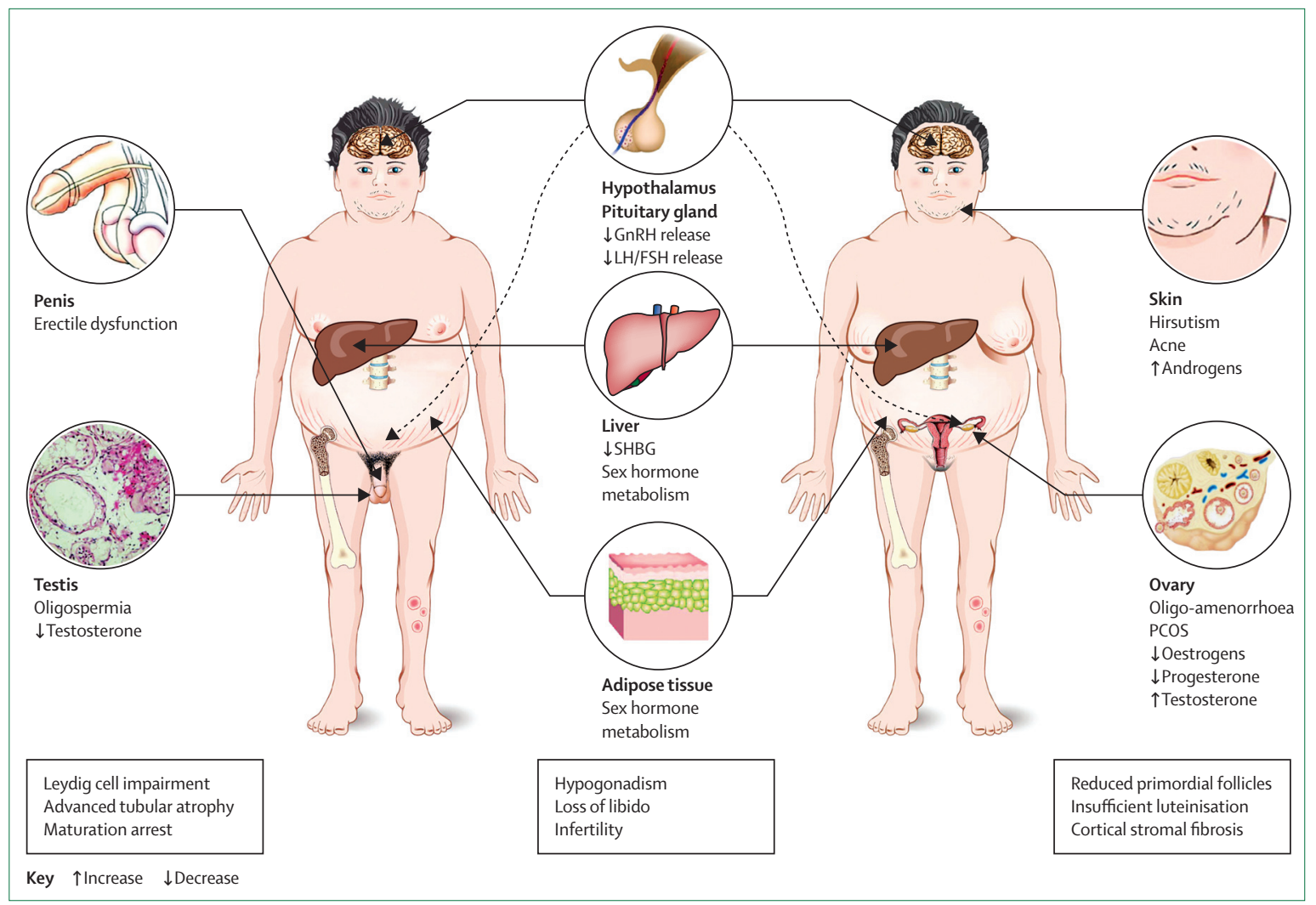

Figure 6: Main pathogenic mechanisms underlying reproductive and sexual disorders in Cushing's syndrome

Circled images represent the main organs that have a role in the sexual abnormalities seen in patients with Cushing's syndrome. From the top (in the middle), hypercortisolism can block the release of gonadotropin-releasing hormone $(\mathrm{GnRH})$ from the hypothalamus and luteinising hormone (LH)/follicle-stimulating hormone (FSH) from the pituitary gland leading to hypogonadotropic hypogonadism. In Cushing's disease, adrenocorticotropic hormone (ACTH) provides an additive block on the release of gonadotropins from the pituitary. Additionally, circulating sex hormone concentrations are altered as a result of changes in sex-steroid binding proteins (sex hormone-binding globulin [SHBG] and albumin) and increased liver metabolism. At gonadal levels, the testis (left side of figure) shows disorganised seminal epithelium, maturation arrest, advanced tubular atrophy, and Leydig cell impairment, leading to oligospermia. The appearance of ovaries (right side of figure) varies from a polycystic appearance to a volumetric reduction caused by hypogonadotropic hypogonadism. The histological findings include reduced primordial follicles, absence of cortical stromal hyperplasia, and fibrosis. Clinical presentation includes decreased libido and erectile dysfunction in men, and oligomenorrhoea or amenorrhoea and hirsutism in women. PCOS=polycystic ovary syndrome.

sexuality associated with Cushing's syndrome (figure 6). Chronic hypercortisolism can block gonadotropinreleasing hormone and gonadotropin release. ${ }^{139,140}$ Visceral adiposity and liver steatosis are associated with abnormalities in sex steroid metabolism, reduction in sex hormone-binding globulin, and androgen excess. ${ }^{56,135,136}$ Intermediate steroids with weak androgenic activity are produced within adipose tissue and can disrupt hypothalamic-pituitary feedback. ${ }^{7,141}$ Glucocorticoids can also directly influence the gonads through a glucocorticoid receptor-mediated inhibition of sex steroid hormone production and cell apoptosis.

\section{Ovarian damage}

In women, clinical symptoms and signs of Cushing's syndrome can resemble those of polycystic ovary syndrome (PCOS), including hirsutism, acne, oligoamenorrhoea, insulin resistance, and obesity. ${ }^{135,136,141}$ Therefore, the differential diagnosis between mild Cushing's syndrome and PCOS is often difficult, and women with proven Cushing's syndrome might initially be diagnosed with isolated PCOS. ${ }^{142}$ PCOS can be associated with an abnormal hypothalamic-pituitaryadrenal axis with increased urinary cortisol and midnight serum cortisol concentrations compared with obese individuals. ${ }^{135,136,141,143}$ Testosterone concentrations were also tested in the differential diagnosis between mild Cushing's syndrome and PCOS; symptomatic women with a total testosterone of less than $1.39 \mathrm{nmol} / \mathrm{L}$ were more likely to need a work-up for Cushing's syndrome. ${ }^{144}$ However, the yield of testing can be low; in a study of 950 women with clinical hyperandrogenism, $72 \%$ had PCOS and none were diagnosed with Cushing's syndrome. ${ }^{145}$ PCOS and Cushing's syndrome frequently coexist, ${ }^{135}$ but the ovaries in Cushing's syndrome have distinct pathological features including a reduction in primordial follicles, an absence of cortical stromal hyperplasia and luteinisation, and the presence of fibrosis and volumetric decrease, consistent with reduced gonadotropin stimulation. ${ }^{146}$ It is also necessary 
to rule out adrenal carcinoma in patients with very high testosterone concentrations. ${ }^{147}$

Treatment with metyrapone or osilodrostat in women increases androgen concentrations further, and might worsen acne and hirsutism. ${ }^{4,73}$ Hormone replacement therapy during the active phase of Cushing's syndrome is not usually recommended in women, because of the high thromboembolic risk, but it should be considered after successful treatment if gonadal function has not been restored. ${ }^{8}$ The abnormalities of gonadal status improve after disease remission and are also reversible, with successful pregnancies reported after remission of Cushing's syndrome. ${ }^{148}$

Despite its rarity, pregnancy during active Cushing's syndrome can be problematic because of severe maternal and fetal complications. The most common maternal complications are hypertension (68\%), impairment of glucose metabolism (25\%), pre-eclampsia (14\%), osteoporosis and skeletal fractures (5\%), psychiatric disorders $(4 \%)$, cardiac failure $(3 \%)$, wound infections (2\%), and maternal death (2\%). ${ }^{149}$ The most frequent fetal morbidity is prematurity, which occurs in about $43 \%$ of pregnancies. Additional complications include intrauterine growth retardation (21\%), stillbirths (6\%), spontaneous abortion or intrauterine death $(5 \%)$, and adrenal insufficiency (2\%). ${ }^{149}$ More than 150 cases of pregnancy in Cushing's syndrome have been reported, most frequently in patients with adrenal tumours $(60 \%) .{ }^{150}$ No pharmacological therapies are approved in pregnancy and some are contraindicated; prompt surgical treatment is the first-line approach, although there are anecdotal reports of successful pharmacological treatment, mostly with the use of metyrapone. ${ }^{149}$

\section{Testicular damage}

In men, clinical symptoms and signs of Cushing's syndrome can include features of hypogonadotropic hypogonadism, including erectile dysfunction. ${ }^{56}$ Oligospermia is common and has been associated with histopathological findings of the testis, including disorganised seminal epithelium, sloughing of immature elements, tubular thickening, and fibrosis. Maturation arrest, advanced tubular atrophy, and a decreased number of Leydig cells were recorded only in severe, untreated, or fatal cases of Cushing's syndrome. ${ }^{137}$ Plasma testosterone and gonadotropin were found to be substantially decreased during active disease, but testosterone concentrations spontaneously normalised after remission, and remained at these normal concentrations during long-term follow-up. ${ }^{138,151}$ Although reversibility of hypogonadism is frequent, for patients without normal testosterone concentrations within 3 months after treatment, testosterone replacement is suggested to protect bone status. $^{8}$ No data are available on semen quality after treatment for Cushing's syndrome. Treatment with ketoconazole in men has been associated with gynaecomastia, hypogonadism, and erectile dysfunction. ${ }^{152}$

\section{Search strategy and selection criteria}

We searched PubMed for papers published in English during the past 30 years (between Jan 1, 1986, and August 1, 2015) using the following MESH search terms: "hypercortisolism" OR "Cushing's disease" OR "Cushing's" OR "Cushing" OR "ectopic Cushing's syndrome" OR "endogenous hypercortisolism" OR "glucocorticoids" and any of the following: "mortality"; "death"; "morbidity"; "complication"; "metabolism"; "metabolic syndrome"; "obesity, glucose tolerance"; "diabetes mellitus"; "dyslipidaemia"; "hypercholesterolaemia"; "hypertriglyceridaemia"; "cardiovascular"; "hypertension"; "coagulopathy"; "venous thromboembolism"; "thrombosis"; "electrolytes"; "infections"; "fungal infections, viral infections, bacterial infections"; "sepsis"; "immunodepression"; "immunosuppression"; "immune system"; "thyroiditis"; "celiac disease"; "LES"; "lupus"; "Graves' disease"; "immune disease"; "autoimmune"; "autoimmunity"; "bone diseases, osteopenia, osteoporosis, fractures"; "cognitive function"; "psychiatric disease"; "depression"; "mania"; "fertility"; "infertility"; "ovary"; "testis"; "PCOS"; "hypogonadism"; "semen"; "spermatogenesis"; "erectile dysfunction"; "sexual function". We gave particular emphasis to original molecular studies, prospective observational data, controlled trials, and larger registry data.

\section{Dermatological manifestations}

Dermatological manifestations are common in Cushing's syndrome, with a prevalence of about $60-90 \%$, and include skin and hair abnormalities..$^{1,45,56,153,154}$ Skin abnormalities include the typically purple striae, together with facial plethora, bruising, disturbed healing, hyperhidrosis, hyperpigmentation, acanthosis nigricans, and acne, whereas hair abnormalities include hirsutism and alopecia. ${ }^{1,153,154}$ The prevalence of skin abnormalities has been reported to be higher in ectopic than in adrenal Cushing's syndrome. ${ }^{56}$ Wide purple striae are more frequent in male than female patients, whereas no sex-related differences have been recorded in the prevalence of acne and ecchymoses. ${ }^{45}$

Glucocorticoids impair keratinocytes and dermal fibroblast proliferation as well as synthesis and turnover of collagen and mucopolysaccharides, leading to skin atrophy and vascular fragility. These effects are associated with thinned dermis and epidermis, retarded wound healing, and increased tendency to form purple striae, petechiae, and ecchymoses. Adrenal androgens are the main cause of hirsutism, acne, and alopecia, but increased protein catabolism has also been associated with follicular damage and alopecia. Facial plethora is generally attributed to polycythaemia and is commonly associated with facial telangiectasias. ${ }^{153}$ Increased concentrations of $\mathrm{ACTH}$, which bind to melanocortin receptors on melanocytes, cause cutaneous hyperpigmentation in patients with ACTH-dependent Cushing's syndrome. ${ }^{152}$ Acanthosis nigricans can be caused by hyperinsulinism and reflects insulin resistance, which together with dyslipidaemia contributes to the development of acne..$^{154}$ Skin abnormalities substantially improve and progressively disappear after surgical or pharmacological remission of hypercortisolism, apart from purple striae, which typically become lighter, but often persist for life and require specific dermatological treatment. ${ }^{153,154}$ 


\section{Conclusions}

Cushing's syndrome is associated with many comorbidities and increased mortality, but with effective treatment most patients normalise cortisol secretion, with consequent improvement in clinical picture including comorbidities and mortality risk. The duration of disease activity is correlated with the mortality risk and negatively affects comorbidities; therefore, prompt diagnosis and treatment of Cushing's syndrome is crucial. Treatment specific to the various comorbidities should be provided in parallel with therapy targeting cortisol excess to accelerate their resolution or improvement, and reduction of mortality risk. Comorbidities can persist in a subgroup of patients even after remission, necessitating continuing management, but the persistence of an increased mortality risk remains debated. Many questions remain about the clinical complications associated with Cushing's syndrome. There is a need for studies with high-quality data regarding comorbidities to guide future evidencebased clinical care. Large population studies that better characterise comorbidities in Cushing's syndrome will be useful to identify the best possible treatments. Understanding the reasons for the variability in clinical improvement among different patients will also be important, and prospective studies that compare the effects of surgical versus pharmacological treatment on comorbidities associated with Cushing's syndrome will be helpful for the treatment decision process. Moreover, studies should explore whether the persistence of comorbidities in patients who are in remission might at least partly relate to overexposure to glucocorticoids from replacement therapy with supraphysiological glucocorticoid concentrations. In addition to providing better management for patients with Cushing's syndrome, findings of these studies might also provide insight into the clinical complications induced by exogenous glucocorticoid therapy, which is commonly used for many disorders worldwide.

\section{Contributors}

RP, AMI, JN-P, BMKB, and AC made substantial contributions to conception and design of the manuscript. RP, AMI, and MCDM were involved in acquisition of data, analysis and interpretation of literature, and elaboration and drafting of the manuscript, figures, and tables. JN-P, $\mathrm{BMKB}$, and $\mathrm{AC}$ made substantial contributions in revising the content as well as the style and the English wording of the manuscript. All authors read and approved the final manuscript.

\section{Declaration of interests}

RP reports grants, personal fees, and other from Novartis; grants and personal fees from Pfizer; grants from HRA Pharma; grants and personal fees from ViroPharma-Shire; personal fees from Italfarmaco; personal fees from Ipsen; and personal fees from Ferring, outside the submitted work. AMI reports personal fees from Menarini, personal fees from Otsuka, grants and personal fees from Viropharma-Shire, and personal fees from Novartis, outside the submitted work. JN-P reports grants and personal fees from HRA Pharma, grants and personal fees from Novartis, and grants and personal fees from Ipsen, outside the submitted work. BMKB reports grants and personal fees from Cortendo, grants and personal fees from Novartis, personal fees from HRA Pharma, and personal fees from Ipsen, outside the submitted work. AC reports grants, personal fees, and other from Novartis; grants and personal fees from Pfizer; grants from HRA Pharma; grants and personal fees from
Italfarmaco; grants, personal fees, and other from Ipsen; and grants from Ferring, Lilly, and Novo Nordisk, outside the submitted work. MCDM declares no competing interests.

\section{Acknowledgments}

We thank Chiara Simeoli, Claudia Pivonello, Renata Simona Auriemma, Rosario Ferrigno, Donatella Paola Provvisiero, Roberta Patalano, Carlotta Pozza, Laura Rizza, Vincenzo Giannetta, and Marianna Minnetti for their contribution to this manuscript. This manuscript has not been supported by any specific grant from any funding agency in the public, commercial, or not-for-profit sector.

\section{References}

1 Pivonello R, De Martino MC, De Leo M, Lombardi G, Colao A. Cushing's syndrome. Endocrinol Metab Clin North Am 2008; 37: 135-49, ix.

2 Newell-Price J, Bertagna X, Grossman AB, Nieman LK. Cushing's syndrome. Lancet 2006; 367: 1605-17.

3 Steffensen C, Bak AM, Rubeck KZ, Jørgensen JO. Epidemiology of Cushing's syndrome. Neuroendocrinology 2010; 92 (suppl 1): 1-5.

4 Pivonello R, De Leo M, Cozzolino A, Colao A. The treatment of Cushing's disease. Endocr Rev 2015; 36: 385-486.

5 Cushing $\mathrm{H}$. The basophil adenomas of the pituitary body and their clinical manifestations. Bull Johns Hopkins Hosp 1932; 50: 137-95.

6 Feelders RA, Pulgar SJ, Kempel A, Pereira AM. The burden of Cushing's disease: clinical and health-related quality of life aspects. Eur J Endocrinol 2012; 167: 311-26.

7 Newell-Price J, Trainer P, Besser M, Grossman A. The diagnosis and differential diagnosis of Cushing's syndrome and pseudo-Cushing's states. Endocr Rev 1998; 19: 647-72.

8 Arnaldi G, Angeli A, Atkinson AB, et al. Diagnosis and complications of Cushing's syndrome: a consensus statement. J Clin Endocrinol Metab 2003; 88: 5593-602.

9 Nieman LK, Biller BM, Findling JW, et al. The diagnosis of Cushing's syndrome: an Endocrine Society Clinical Practice Guideline. J Clin Endocrinol Metab 2008; 93: 1526-40.

10 Biller BM, Grossman AB, Stewart PM, et al. Treatment of adrenocorticotropin-dependent Cushing's syndrome: a consensus statement. J Clin Endocrinol Metab 2008; 93: 2454-62.

11 Nieman LK, Biller BM, Findling JW, et al, and the Endocrine Society. Treatment of Cushing's syndrome: an Endocrine Society clinical practice guideline. J Clin Endocrinol Metab 2015; 100: 2807-31.

12 Crowley RK, Argese N, Tomlinson JW, Stewart PM. Centra hypoadrenalism. J Clin Endocrinol Metab 2014; 99: 4027-36.

13 Hochberg Z, Pacak K, Chrousos GP. Endocrine withdrawal syndromes. Endocr Rev 2003; 24: 523-38.

14 Grossman A, Johannsson G, Quinkler M, Zelissen P. Therapy of endocrine disease: perspectives on the management of adrenal insufficiency: clinical insights from across Europe. Eur J Endocrinol 2013; 169: R165-75.

15 Clayton RN. Mortality in Cushing's disease. Neuroendocrinology 2010; 92 (suppl 1): 71-76.

16 Etxabe J, Vazquez JA. Morbidity and mortality in Cushing's disease: an epidemiological approach. Clin Endocrinol (Oxf) 1994; 40: 479-84.

17 Swearingen B, Biller BM, Barker FG 2nd, et al. Long-term mortality after transsphenoidal surgery for Cushing disease. Ann Intern Med 1999; 130: 821-24.

18 Pikkarainen L, Sane T, Reunanen A. The survival and well-being of patients treated for Cushing's syndrome. J Intern Med 1999; 245: 463-68

19 Lindholm J, Juul S, Jørgensen JO, et al. Incidence and late prognosis of Cushing's syndrome: a population-based study. J Clin Endocrinol Metab 2001; 86: 117-23.

20 Hammer GD, Tyrrell JB, Lamborn KR, et al. Transsphenoidal microsurgery for Cushing's disease: initial outcome and long-term results. J Clin Endocrinol Metab 2004; 89: 6348-57.

21 Dekkers OM, Biermasz NR, Pereira AM, et al. Mortality in patients treated for Cushing's disease is increased, compared with patients treated for nonfunctioning pituitary macroadenoma. J Clin Endocrinol Metab 2007; 92: 976-81.

22 Clayton RN, Raskauskiene D, Reulen RC, Jones PW. Mortality and morbidity in Cushing's disease over 50 years in Stoke-on-Trent, UK audit and meta-analysis of literature. J Clin Endocrinol Metab 2011; 96: 632-42. 
23 Hassan-Smith ZK, Sherlock M, Reulen RC, et al. Outcome of Cushing's disease following transsphenoidal surgery in a single center over 20 years. J Clin Endocrinol Metab 2012; 97: 1194-201.

24 Bolland MJ, Holdaway IM, Berkeley JE, et al. Mortality and morbidity in Cushing's syndrome in New Zealand. Clin Endocrinol (Oxf) 2011; 75: 436-42.

25 Yaneva M, Kalinov K, Zacharieva S. Mortality in Cushing's syndrome: data from 386 patients from a single tertiary referral center. Eur J Endocrinol 2013; 169: 621-27.

26 Ntali G, Asimakopoulou A, Siamatras T, et al. Mortality in Cushing's syndrome: systematic analysis of a large series with prolonged follow-up. Eur J Endocrinol 2013; 169: 715-23.

27 Lambert JK, Goldberg L, Fayngold S, Kostadinov J, Post KD, Geer EB. Predictors of mortality and long-term outcomes in treated Cushing's disease: a study of 346 patients. J Clin Endocrinol Metab 2013; 98: 1022-30.

28 Dekkers OM, Horváth-Puhó E, Jørgensen JO, et al. Multisystem morbidity and mortality in Cushing's syndrome: a cohort study. J Clin Endocrinol Metab 2013; 98: 2277-84.

29 Graversen D, Vestergaard P, Stochholm K, Gravholt CH, Jørgensen JO. Mortality in Cushing's syndrome: a systematic review and meta-analysis. Eur J Intern Med 2012; 23: 278-82.

30 Pivonello R, Faggiano A, Lombardi G, Colao A. The metabolic syndrome and cardiovascular risk in Cushing's syndrome. Endocrinol Metab Clin North Am 2005; 34: 327-39, viii.

31 Wang M. The role of glucocorticoid action in the pathophysiology of the metabolic syndrome. Nutr Metab (Lond) 2005; 2: 3.

32 Pivonello R, De Leo M, Vitale P, et al. Pathophysiology of diabetes mellitus in Cushing's syndrome. Neuroendocrinology 2010; 92 (suppl 1): 77-81.

33 Lee MJ, Pramyothin P, Karastergiou K, Fried SK. Deconstructing the roles of glucocorticoids in adipose tissue biology and the development of central obesity. Biochim Biophys Acta 2014; 1842: 473-81.

34 Tataranni PA, Larson DE, Snitker S, Young JB, Flatt JP, Ravussin E. Effects of glucocorticoids on energy metabolism and food intake in humans. Am J Physiol 1996; 271: E317-25.

35 Galton DJ, Wilson JP. Lipogenesis in adipose tissue of patients with obesity and Cushing's disease. Clin Sci 1972; 43: 17P.

36 Faggiano A, Pivonello R, Spiezia S, et al. Cardiovascular risk factors and common carotid artery caliber and stiffness in patients with Cushing's disease during active disease and 1 year after disease remission. J Clin Endocrinol Metab 2003; 88: 2527-33.

37 Mancini T, Kola B, Mantero F, Boscaro M, Arnaldi G. High cardiovascular risk in patients with Cushing's syndrome according to 1999 WHO/ISH guidelines. Clin Endocrinol (Oxf) 2004; 61: 768-77.

38 Giordano R, Picu A, Marinazzo E, et al. Metabolic and cardiovascular outcomes in patients with Cushing's syndrome of different aetiologies during active disease and 1 year after remission. Clin Endocrinol (Oxf) 2011; 75: 354-60.

39 Barahona MJ, Sucunza N, Resmini E, et al. Persistent body fat mass and inflammatory marker increases after long-term cure of Cushing's syndrome. J Clin Endocrinol Metab 2009; 94: 3365-71.

40 Colao A, Pivonello R, Spiezia S, et al. Persistence of increased cardiovascular risk in patients with Cushing's disease after five years of successful cure. J Clin Endocrinol Metab 1999; 84: 2664-72.

41 Geer EB, Shen W, Gallagher D, et al. MRI assessment of lean and adipose tissue distribution in female patients with Cushing's disease. Clin Endocrinol (Oxf) 2010; 73: 469-75.

42 Albiger N, Testa RM, Almoto B, et al. Patients with Cushing's syndrome have increased intimal media thickness at different vascular levels: comparison with a population matched for similar cardiovascular risk factors. Horm Metab Res 2006; 38: 405-10.

43 Geer EB, Shen W, Strohmayer E, Post KD, Freda PU. Body composition and cardiovascular risk markers after remission of Cushing's disease: a prospective study using whole-body MRI. $J$ Clin Endocrinol Metab 2012; 97: 1702-11.

44 Giordano C, Guarnotta V, Pivonello R, et al. Is diabetes in Cushing's syndrome only a consequence of hypercortisolism? Eur J Endocrinol 2014; 170: 311-19.

45 Pecori Giraldi F, Moro M, Cavagnini F, and the Study Group on the Hypothalamo-Pituitary-Adrenal Axis of the Italian Society of Endocrinology. Gender-related differences in the presentation and course of Cushing's disease. J Clin Endocrinol Metab 2003; 88: 1554-58.
46 Pivonello R, De Martino MC, Cappabianca P, et al. The medical treatment of Cushing's disease: effectiveness of chronic treatmen with the dopamine agonist cabergoline in patients unsuccessfully treated by surgery. J Clin Endocrinol Metab 2009; 94: 223-30.

47 Castinetti F, Morange I, Jaquet P, Conte-Devolx B, Brue T Ketoconazole revisited: a preoperative or postoperative treatment in Cushing's disease. Eur J Endocrinol 2008; 158: 91-99.

48 Castinetti F, Guignat L, Giraud P, et al. Ketoconazole in Cushing's disease: is it worth a try? J Clin Endocrinol Metab 2014; 99: 1623-30.

49 Moncet D, Morando DJ, Pitoia F, Katz SB, Rossi MA, Bruno OD. Ketoconazole therapy: an efficacious alternative to achieve eucortisolism in patients with Cushing's syndrome. Medicina (B Aires) 2007; 67: 26-31.

50 Baudry C, Coste J, Bou Khalil R, et al. Efficiency and tolerance of mitotane in Cushing's disease in 76 patients from a single center. Eur J Endocrinol 2012; 167: 473-81.

51 Fleseriu M, Biller BM, Findling JW, Molitch ME, Schteingart DE, Gross C, and the SEISMIC Study Investigators. Mifepristone, a glucocorticoid receptor antagonist, produces clinical and metabolic benefits in patients with Cushing's syndrome. J Clin Endocrinol Metab 2012; 97: 2039-49.

52 Castinetti F, Fassnacht M, Johanssen S, et al. Merits and pitfalls of mifepristone in Cushing's syndrome. Eur J Endocrinol 2009; 160: 1003-10

53 Katznelson L, Loriaux DL, Feldman D, Braunstein GD, Schteingart DE Gross C. Global clinical response in Cushing's syndrome patients treated with mifepristone. Clin Endocrinol (Oxf) 2014; 80: 562-69.

54 Wallia A, Colleran K, Purnell JQ, Gross C, Molitch ME. Improvement in insulin sensitivity during mifepristone treatment of Cushing syndrome: early and late effects. Diabetes Care 2013; 36: e147-48.

55 Pivonello R, Petersenn S, Newell-Price J, et al, and the Pasireotide B2305 Study Group. Pasireotide treatment significantly improves clinical signs and symptoms in patients with Cushing's disease: results from a phase III study. Clin Endocrinol (Oxf) 2014; 81: 408-17.

56 Valassi E, Santos A, Yaneva M, et al, and the ERCUSYN Study Group. The European Registry on Cushing's syndrome: 2-year experience. Baseline demographic and clinical characteristics. Eur J Endocrinol 2011; 165: 383-92.

57 Pivonello R, De Martino MC, De Leo M, et al. Cushing's syndrome: aftermath of the cure. Arq Bras Endocrinol Metabol 2007; 51: 1381-91.

58 Jeffcoate WJ, Rees LH, Tomlin S, Jones AE, Edwards CR, Besser GM. Metyrapone in long-term management of Cushing's disease. BMJ 1977; 2: 215-17

59 Colao A, Petersenn S, Newell-Price J, et al, and the Pasireotide B2305 Study Group. A 12-month phase 3 study of pasireotide in Cushing's disease. $N$ Engl J Med 2012; 366: 914-24.

60 Henry RR, Ciaraldi TP, Armstrong D, Burke P, Ligueros-Saylan M, Mudaliar S. Hyperglycemia associated with pasireotide: results from a mechanistic study in healthy volunteers. J Clin Endocrinol Metab 2013; 98: 3446-53.

61 Colao A, De Block C, Gaztambide MS, Kumar S, Seufert J, Casanueva FF. Managing hyperglycemia in patients with Cushing's disease treated with pasireotide: medical expert recommendations. Pituitary 2014; 17: 180-86.

62 Filipsson H, Monson JP, Koltowska-Häggström M, Mattsson A, Johannsson G. The impact of glucocorticoid replacement regimens on metabolic outcome and comorbidity in hypopituitary patients. J Clin Endocrinol Metab 2006; 91: 3954-61.

63 Munir A, Newell-Price J. Management of diabetes mellitus in Cushing's syndrome. Neuroendocrinology 2010; 92 (suppl 1): 82-85.

64 Isidori AM, Graziadio C, Paragliola RM, et al, and the ABC Study Group. The hypertension of Cushing's syndrome: controversies in the pathophysiology and focus on cardiovascular complications. J Hypertens 2015; 33: 44-60.

65 Gómez RM, Albiger NM, Díaz AG, Moncet D, Pitoia FA, Bruno OD. Effect of hypercortisolism control on high blood pressure in Cushing's syndrome. Medicina (B Aires) 2007; 67: 439-44.

66 Isidori AM, Minnetti M, Sbardella E, Graziadio C, Grossman AB. Mechanisms in endocrinology: the spectrum of haemostatic abnormalities in glucocorticoid excess and defect. Eur J Endocrino 2015; 173: R101-13.

67 Pereira AM, Delgado V, Romijn JA, Smit JW, Bax JJ, Feelders RA. Cardiac dysfunction is reversed upon successful treatment of Cushing's syndrome. Eur J Endocrinol 2010; 162: 331-40. 
68 Jyotsna VP, Naseer A, Sreenivas V, Gupta N, Deepak KK. Effect of Cushing's syndrome-endogenous hypercortisolemia on cardiovascular autonomic functions. Auton Neurosci 2011; 160: 99-102.

69 Torpy DJ, Mullen N, Ilias I, Nieman LK. Association of hypertension and hypokalemia with Cushing's syndrome caused by ectopic ACTH secretion: a series of 58 cases. Ann N Y Acad Sci 2002; 970: 134-44.

70 Muiesan ML, Lupia M, Salvetti M, et al. Left ventricular structural and functional characteristics in Cushing's syndrome. J Am Coll Cardiol 2003; 41: 2275-79.

71 Pecori Giraldi F, Toja PM, De Martin M, et al. Circadian blood pressure profile in patients with active Cushing's disease and after long-term cure. Horm Metab Res 2007; 39: 908-14.

72 Storr HL, Isidori AM, Monson JP, Besser GM, Grossman AB, Savage MO. Prepubertal Cushing's disease is more common in males, but there is no increase in severity at diagnosis. $J$ Clin Endocrinol Metab 2004; 89: 3818-20.

73 Bertagna X, Pivonello R, Fleseriu M, et al. LCI699, a potent $11 \beta$-hydroxylase inhibitor, normalizes urinary cortisol in patients with Cushing's disease: results from a multicenter, proof-of-concept study. J Clin Endocrinol Metab 2014; 99: 1375-83.

74 Castinetti F, Brue T, Conte-Devolx B. The use of the glucocorticoid receptor antagonist mifepristone in Cushing's syndrome. Curr Opin Endocrinol Diabetes Obes 2012; 19: 295-99.

75 Kamenický P, Redheuil A, Roux C, et al. Cardiac structure and function in Cushing's syndrome: a cardiac magnetic resonance imaging study. J Clin Endocrinol Metab 2014; 99: E2144-53.

76 Ainscough JF, Drinkhill MJ, Sedo A, et al. Angiotensin II type-1 receptor activation in the adult heart causes blood

pressure-independent hypertrophy and cardiac dysfunction. Cardiovasc Res 2009; 81: 592-600.

77 Brilla CG, Weber KT. Mineralocorticoid excess, dietary sodium, and myocardial fibrosis. J Lab Clin Med 1992; 120: 893-901.

78 Pecori Giraldi F, Toja PM, Michailidis G, et al. High prevalence of prolonged QT interval duration in male patients with Cushing's disease. Exp Clin Endocrinol Diabetes 2011; 119: 221-24.

79 Faggiano A, Melis D, Alfieri R, et al. Sulfur amino acids in Cushing's disease: insight in homocysteine and taurine levels in patients with active and cured disease. J Clin Endocrinol Metab 2005 90: 6616-22.

80 Yiu KH, Marsan NA, Delgado V, et al. Increased myocardial fibrosis and left ventricular dysfunction in Cushing's syndrome. Eur J Endocrinol 2012; 166: 27-34.

81 van der Pas R, Leebeek FW, Hofland LJ, de Herder WW, Feelders RA. Hypercoagulability in Cushing's syndrome: prevalence, pathogenesis and treatment. Clin Endocrinol (Oxf) 2013; 78: 481-88

82 van der Pas R, de Bruin C, Leebeek FW, et al. The hypercoagulable state in Cushing's disease is associated with increased levels of procoagulant factors and impaired fibrinolysis, but is not reversible after short-term biochemical remission induced by medical therapy. J Clin Endocrinol Metab 2012; 97: 1303-10.

83 Boscaro M, Sonino N, Scarda A, et al. Anticoagulant prophylaxis markedly reduces thromboembolic complications in Cushing's syndrome. J Clin Endocrinol Metab 2002; 87: 3662-66

84 Levis JT. ECG diagnosis: hypokalemia. Perm J 2012; 16 : 57.

85 Arteaga E, Fardella C, Campusano C, Cárdenas I, Martinez P. Persistent hypokalemia after successful adrenalectomy in a patient with Cushing's syndrome due to ectopic ACTH secretion: possible role of 11beta-hydroxysteroid dehydrogenase inhibition. J Endocrinol Invest 1999; 22: 857-59.

86 Fareau GG, Vassilopoulou-Sellin R. Hypercortisolemia and infection. Infect Dis Clin North Am 2007; 21: 639-57, viii.

87 Kovalovsky D, Refojo D, Holsboer F, Arzt E. Molecular mechanisms and Th1/Th2 pathways in corticosteroid regulation of cytokine production. J Neuroimmunol 2000; 109: 23-29.

88 Ilias I, Torpy DJ, Pacak K, Mullen N, Wesley RA, Nieman LK. Cushing's syndrome due to ectopic corticotropin secretion: twenty years' experience at the National Institutes of Health. $J$ Clin Endocrinol Metab 2005; 90: 4955-62.

89 Sarlis NJ, Chanock SJ, Nieman LK. Cortisolemic indices predict severe infections in Cushing syndrome due to ectopic production of adrenocorticotropin. J Clin Endocrinol Metab 2000; 85: 42-47.
90 Ejaz S, Vassilopoulou-Sellin R, Busaidy NL, et al. Cushing syndrome secondary to ectopic adrenocorticotropic hormone secretion: the University of Texas MD Anderson Cancer Center Experience. Cancer 2011; 117: 4381-89.

91 Broder MS, Neary MP, Chang E, Ludlam WH. Incremental healthcare resource utilization and costs in US patients with Cushing's disease compared with diabetes mellitus and population controls. Pituitary 2015; 18: 796-802.

92 Bakker RC, Gallas PR, Romijn JA, Wiersinga WM. Cushing's syndrome complicated by multiple opportunistic infections. J Endocrinol Invest 1998; 21: 329-33.

93 Lionakis MS, Kontoyiannis DP. Glucocorticoids and invasive fungal infections. Lancet 2003; 362: 1828-38.

94 Rizwan A, Sarfaraz A, Jabbar A, Akhter J, Islam N. Case report: nocardia infection associated with ectopic cushings. BMC Endocr Disord 2014; 14: 51.

95 Graham BS, Tucker WS Jr. Opportunistic infections in endogenous Cushing's syndrome. Ann Intern Med 1984; 101: 334-38.

96 Razavi B, O’Toole J, Schilling M, Razavi M. Cryptococcal meningitis, an endocrine emergency? Lancet 2000; 355: 1426.

97 Oosterhuis JK, van den Berg G, Monteban-Kooistra WE, et al. Life-threatening Pneumocystis jiroveci pneumonia following treatmen of severe Cushing's syndrome. Neth J Med 2007; 65: 215-17.

98 Takasu N, Komiya I, Nagasawa Y, Asawa T, Yamada T. Exacerbation of autoimmune thyroid dysfunction after unilateral adrenalectomy in patients with Cushing's syndrome due to an adrenocortical adenoma. N Engl J Med 1990; 322: 1708-12.

99 Takasu N, Ohara N, Yamada T, Komiya I. Development of autoimmune thyroid dysfunction after bilateral adrenalectomy in a patient with Carney's complex and after removal of ACTH-producing pituitary adenoma in a patient with Cushing's disease. J Endocrinol Invest 1993; 16: 697-702.

100 Colao A, Pivonello R, Faggiano A, et al. Increased prevalence of thyroid autoimmunity in patients successfully treated for Cushing's disease. Clin Endocrinol (Oxf) 2000; 53: 13-19.

101 da Mota F, Murray C, Ezzat S. Overt immune dysfunction after Cushing's syndrome remission: a consecutive case series and review of the literature. J Clin Endocrinol Metab 2011; 96: E1670-74.

102 Neto MB, Machado MC, Mesquita F, et al. Thymus hyperplasia after resolution of hypercortisolism in ACTH-dependent Cushing's syndrome: the importance of thymic vein catheterization. Eur J Endocrinol 2006; 154: 807-11.

103 Di Somma C, Pivonello R, Loche S, et al. Severe impairment of bone mass and turnover in Cushing's disease: comparison between childhood-onset and adulthood-onset disease. Clin Endocrinol (Oxf) 2002; 56: 153-58.

104 Di Somma C, Pivonello R, Loche S, et al. Effect of 2 years of cortisol normalization on the impaired bone mass and turnover in adolescent and adult patients with Cushing's disease: a prospective study. Clin Endocrinol (Oxf) 2003; 58: 302-08.

105 Kawamata A, Iihara M, Okamoto T, Obara T. Bone mineral density before and after surgical cure of Cushing's syndrome due to adrenocortical adenoma: prospective study. World J Surg 2008; 32: 890-96.

106 Minetto M, Reimondo G, Osella G, Ventura M, Angeli A, Terzolo M. Bone loss is more severe in primary adrenal than in pituitary-dependent Cushing's syndrome. Osteoporos Int 2004; 15: 855-61.

107 Ohmori N, Nomura K, Ohmori K, Kato Y, Itoh T, Takano K. Osteoporosis is more prevalent in adrenal than in pituitary Cushing's syndrome. Endocr J 2003; 50: 1-7.

108 Tauchmanovà L, Pivonello R, De Martino MC, et al. Effects of sex steroids on bone in women with subclinical or overt endogenous hypercortisolism. Eur J Endocrinol 2007; 157: 359-66.

109 van der Eerden AW, den Heijer M, Oyen WJ, Hermus AR. Cushing's syndrome and bone mineral density: lowest $\mathrm{Z}$ scores in young patients. Neth J Med 2007; 65: 137-41.

110 dos Santos CV, Vieira Neto L, Madeira M, et al. Bone density and microarchitecture in endogenous hypercortisolism. Clin Endocrinol (Oxf) 2015; 83: 468-74.

111 Hermus AR, Smals AG, Swinkels LM, et al. Bone mineral density and bone turnover before and after surgical cure of Cushing's syndrome. J Clin Endocrinol Metab 1995; 80: 2859-65. 
112 Randazzo ME, Grossrubatscher E, Dalino Ciaramella P, Vanzulli A, Loli P. Spontaneous recovery of bone mass after cure of endogenous hypercortisolism. Pituitary 2012; 15: 193-201.

113 Tauchmanovà L, Pivonello R, Di Somma C, et al. Bone demineralization and vertebral fractures in endogenous cortisol excess: role of disease etiology and gonadal status. J Clin Endocrinol Metab 2006; 91: 1779-84.

114 Trementino L, Appolloni G, Ceccoli L, et al. Bone complications in patients with Cushing's syndrome: looking for clinical, biochemical, and genetic determinants. Osteoporos Int 2014; 25: 913-21.

115 Barahona MJ, Sucunza N, Resmini E, et al. Deleterious effects of glucocorticoid replacement on bone in women after long-term remission of Cushing's syndrome. J Bone Miner Res 2009; 24: 1841-46.

116 Di Somma C, Colao A, Pivonello R, et al. Effectiveness of chronic treatment with alendronate in the osteoporosis of Cushing's disease. Clin Endocrinol (Oxf) 1998; 48: 655-62.

117 Chiodini I, Carnevale V, Torlontano M, et al. Alterations of bone turnover and bone mass at different skeletal sites due to pure glucocorticoid excess: study in eumenorrheic patients with Cushing's syndrome. J Clin Endocrinol Metab 1998; 83: 1863-67.

118 Kristo C, Jemtland R, Ueland T, Godang K, Bollerslev J. Restoration of the coupling process and normalization of bone mass following successful treatment of endogenous Cushing's syndrome: a prospective, long-term study. Eur J Endocrinol 2006; 154: 109-18.

119 Vestergaard P, Lindholm J, Jørgensen JO, et al. Increased risk of osteoporotic fractures in patients with Cushing's syndrome. Eur J Endocrinol 2002; 146: 51-56.

120 Füto L, Toke J, Patócs A, et al. Skeletal differences in bone minera area and content before and after cure of endogenous Cushing's syndrome. Osteoporos Int 2008; 19: 941-49.

121 Canalis E, Mazziotti G, Giustina A, Bilezikian JP. Glucocorticoid-induced osteoporosis: pathophysiology and therapy. Osteoporos Int 2007; 18: 1319-28.

122 Weinstein RS. Clinical practice. Glucocorticoid-induced bone disease. N Engl J Med 2011; 365: 62-70.

123 Seibel MJ, Cooper MS, Zhou H. Glucocorticoid-induced osteoporosis: mechanisms, management, and future perspectives Lancet Diabetes Endocrinol 2013; 1: 59-70.

124 Luisetto G, Zangari M, Camozzi V, Boscaro M, Sonino N, Fallo F. Recovery of bone mineral density after surgical cure, but not by ketoconazole treatment, in Cushing's syndrome. Osteoporos Int 2001; 12: 956-60.

125 Scillitani A, Mazziotti G, Di Somma C, et al, and the ABC Group. Treatment of skeletal impairment in patients with endogenous hypercortisolism: when and how? Osteoporos Int 2014; 25: 441-46.

126 Minetto MA, Lanfranco F, Motta G, Allasia S, Arvat E, D’Antona G. Steroid myopathy: some unresolved issues. J Endocrinol Invest 2011; 34: $370-75$.

127 Schakman O, Kalista S, Barbé C, Loumaye A, Thissen JP. Glucocorticoid-induced skeletal muscle atrophy. Int J Biochem Cell Biol 2013; 45: 2163-72.

128 Aulinas A, Colom C, Ybarra J, et al. Immediate and delayed postoperative morbidity in functional and non-functioning pituitary adenomas. Pituitary 2012; 15: 380-85.

129 Pivonello R, Simeoli C, De Martino MC, et al. Neuropsychiatric disorders in Cushing's syndrome. Front Neurosci 2015; 9: 129.

130 Sonino N, Fava GA. Psychiatric disorders associated with Cushing's syndrome. Epidemiology, pathophysiology and treatment. CNS Drugs 2001; 15: 361-73.

131 De Kloet ER, Vreugdenhil E, Oitzl MS, Joëls M. Brain corticosteroid receptor balance in health and disease. Endocr Rev 1998. 19: 269-301.

132 Jacobs BL, van Praag H, Gage FH. Adult brain neurogenesis and psychiatry: a novel theory of depression. Mol Psychiatry 2000; 5: 262-69.
133 Patil CG, Lad SP, Katznelson L, Laws ER Jr. Brain atrophy and cognitive deficits in Cushing's disease. Neurosurg Focus 2007; 23: E11.

134 Bleicken B, Hahner S, Loeffler M, et al. Influence of hydrocortisone dosage scheme on health-related quality of life in patients with adrenal insufficiency. Clin Endocrinol (Oxf) 2010; 72: 297-304.

135 Kaltsas GA, Korbonits M, Isidori AM, et al. How common are polycystic ovaries and the polycystic ovarian syndrome in women with Cushing's syndrome? Clin Endocrinol (Oxf) 2000; 53: 493-500.

136 Lado-Abeal J, Rodriguez-Arnao J, Newell-Price JD, et al Menstrual abnormalities in women with Cushing's disease are correlated with hypercortisolemia rather than raised circulating androgen levels. J Clin Endocrinol Metab 1998; 83: 3083-88.

137 Gabrilove JL, Nicolis GL, Sohval AR. The testis in Cushing's syndrome. J Urol 1974; 112: 95-99.

138 McKenna TJ, Lorber D, Lacroix A, Rabin D. Testicular activity in Cushing's disease. Acta Endocrinol (Copenh) 1979; 91: 501-10.

139 Pivonello R, De Martino MC, Auriemma RS, et al. Pituitary tumors and pregnancy: the interplay between a pathologic condition and a physiologic status. J Endocrinol Invest 2014; 37: 99-112.

140 Whirledge S, Cidlowski JA. Glucocorticoids, stress, and fertility. Minerva Endocrinol 2010; 35: 109-25.

141 Unuane D, Tournaye H, Velkeniers B, Poppe K. Endocrine disorders \& female infertility. Best Pract Res Clin Endocrinol Metab 2011; 25: 861-73.

142 Brzana J, Yedinak CG, Hameed N, Plesiu A, McCartney S, Fleseriu M. Polycystic ovarian syndrome and Cushing's syndrome: a persistent diagnostic quandary. Eur J Obstet Gynecol Reprod Biol 2014; 175: 145-48.

143 Putignano P, Bertolini M, Losa M, Cavagnini F. Screening for Cushing's syndrome in obese women with and without polycystic ovary syndrome. J Endocrinol Invest 2003; 26: 539-44.

144 Pall ME, Lao MC, Patel SS, et al. Testosterone and bioavailable testosterone help to distinguish between mild Cushing's syndrome and polycystic ovarian syndrome. Horm Metab Res 2008; 40: 813-18.

145 Carmina E, Rosato F, Jannì A, Rizzo M, Longo RA. Extensive clinical experience: relative prevalence of different androgen excess disorders in 950 women referred because of clinica hyperandrogenism. J Clin Endocrinol Metab 2006; 91: 2-6.

146 Iannaccone A, Gabrilove JL, Sohval AR, Soffer LJ. The ovaries in Cushing's syndrome. N Engl J Med 1959; 261: 775-80.

147 Kaltsas GA, Isidori AM, Kola BP, et al. The value of the low-dose dexamethasone suppression test in the differential diagnosis of hyperandrogenism in women. J Clin Endocrinol Metab 2003; 88: 2634-43.

148 Ferraù F, Losa M, Cotta OR, et al. Course of pregnancies in women with Cushing's disease treated by gamma-knife. Gynecol Endocrinol 2012; 28: 827-29.

149 Lindsay JR, Jonklaas J, Oldfield EH, Nieman LK. Cushing's syndrome during pregnancy: personal experience and review of the literature. J Clin Endocrinol Metab 2005; 90: 3077-83.

150 Bronstein MD, Machado MC, Fragoso MC. Management of endocrine disease: management of pregnant patients with Cushing's syndrome. Eur J Endocrinol 2015; 173: R85-91.

151 Luton JP, Thieblot P, Valcke JC, Mahoudeau JA, Bricaire H. Reversible gonadotropin deficiency in male Cushing's disease. J Clin Endocrinol Metab 1977; 45: 488-95.

152 Pozza C, Graziadio C, Giannetta E, Lenzi A, Isidori AM. Management strategies for aggressive Cushing's syndrome: from macroadenomas to ectopics. J Oncol 2012; 2012: 685213

153 Davidovici BB, Orion E, Wolf R. Cutaneous manifestations of pituitary gland diseases. Clin Dermatol 2008; 26: 288-95.

154 Stratakis CA, Mastorakos G, Mitsiades NS, Mitsiades CS, Chrousos GP. Skin manifestations of Cushing disease in children and adolescents before and after the resolution of hypercortisolemia. Pediatr Dermatol 1998; 15: 253-58. 